\title{
The dynamic indentation response of sandwich panels with a corrugated or Y-frame core
}

\author{
L. St-Pierre, N.A. Fleck ${ }^{*}$ and V.S. Deshpande \\ Department of Engineering, University of Cambridge, Trumpington Street, \\ Cambridge, CP2 1PZ, UK. \\ November 24, 2014
}

\begin{abstract}
The dynamic indentation response of stainless steel sandwich panels with a corrugated core or a Y-frame core has been explored using the finite element method to gain insight into the potential of the cores to mitigate against collisions over a wide range of impact velocities pertinent to land and sea-borne vehicles. Back-supported sandwich panels were impacted on the front face by a flat-bottomed or a circular punch at constant velocity ranging from quasi-static loading to $100 \mathrm{~m} / \mathrm{s}$. At velocities below $10 \mathrm{~m} / \mathrm{s}$ the forces on the front and back faces are equal but inertia stabilisation raises the peak load above its quasi-static value. This strength elevation is greater for the corrugated core than for the Y-frame core, and more pronounced for the flatbottomed punch than for the circular punch. For velocities greater than $10 \mathrm{~m} / \mathrm{s}$, the indentation force applied to the front face exceeds the force transmitted to the back face due to plastic-shock effects. In this regime, the force transmitted to the back face by the Y-frame core is markedly less than for the corrugated core, and this brings a performance benefit to the Y-frame, i.e. it protects the underlying structure in the event of a collision.
\end{abstract}

Keywords: Sandwich panel, Y-frame core, Corrugated core, Indentation.

\footnotetext{
* Corresponding author. Tel: +44 1223748240 Fax: +44 1223332662 Email: naf1@eng.cam.ac.uk
} 


\section{Introduction}

More than 200 maritime accidents were recorded in the Gulf of Finland from 1997 to 2006 [1]. About 50\% of those accidents were grounding (the impact of a ship on the seabed) and another $20 \%$ were ship-ship collisions. The frequency of such accidents has the potential to increase in the future as maritime traffic increases and as vessels become larger and faster. Thus, it is vital that ship structures have adequate strength and energy absorption capacity to resist collisions. The crashworthiness of most tankers relies on a conventional double hull design, with minimal coupling between inner and outer hulls. However, improved crash performance can be obtained by sandwich construction [2]. Similarly, the crashworthiness of land vehicles (and their resistance to security threats such as air blast) can be improved by the appropriate choice of an energy absorbing core in a sandwich configuration. This motivates the present basic study: we explore the resistance of sandwich cores to local indentation, and determine the indentation response as a function of impact velocity. Our intent is not to analyse the precise geometry of a particular vehicle, but to explore the significance of localised impact rather than distributed crushing on a sandwich panel, over a wide range of impact velocities.

A recent example of sandwich construction is the Y-frame hull design developed by Damen Schelde Naval Shipbuilding ${ }^{1}$, see Fig. 1a. Full-scale collision trials have been performed on the Y-frame structure and it has been demonstrated that its crashworthiness exceeds that of a conventional double hull design [3]. These fullscale collision trials also revealed that the Y-frame hull design collapsed by indentation, with the inner hull undergoing negligible plastic deformation. The corrugated core, see Fig. 1b, is a competing design to the Y-frame core. No full-scale

\footnotetext{
${ }^{1}$ Damen Schelde Naval Shipbuilding, Glacisstraat 165, 4381 SE Vlissingen, The Netherlands.
} 
collision tests on the corrugated core have been reported in the open literature, but its performances relative to those of the Y-frame core have been investigated in the laboratory, as follows. The quasi-static three-point bending response of sandwich beams with a corrugated core or with a Y-frame core has been studied by Rubino et al. [4] and St-Pierre et al. [5]. Both studies have shown that corrugated and Y-frame sandwich beams of short spans (such as those used in a ship hull) collapse by indentation. These results suggest that additional insight into the deformation of a sandwich panel during a ship collision is gleaned by considering its fundamental indentation response. It is currently unknown whether the corrugated and Y-frame sandwich panels have potential to mitigate against collisions in automotive and rail transport. Collisions on land are likely to occur at much higher velocities than on sea; hence, there is a need to quantify the effect of loading velocity on the indentation response of the sandwich panels.

The dynamic compressive response of corrugated and Y-frame cores, subjected to uniform loading at velocities ranging from 1 to $100 \mathrm{~m} / \mathrm{s}$, was measured by Tilbrook et al. [6] and investigated numerically by McShane et al. [7] (for the corrugated core only). Both studies identified two regimes of dynamic behaviour differentiated by comparing the forces on the impacted and rear faces. First, at low impact velocities, inertia stabilisation of the core members against buckling increases the collapse load compared to the quasi-static case, but the forces on the impacted and rear faces are equal. Second, at high velocities, the force on the impacted face is higher than that on the rear face due to plastic-shock effects. In the current study, the finite element method is used to determine the relative significance of these two regimes when the loading is localised rather than uniform in nature. Qualitative differences in response are anticipated from the case of uniform compression since concentrated loading, such as indentation, acts in the same manner as an initial imperfection in buckling. Our objective is to analyse the sensitivity of the indentation response to impact velocity, 
for different headshapes and sizes of indenters. Two prismatic headshapes are considered: a flat-bottomed punch (Fig. 2a) and a circular punch (Fig. 2b). For both indenters, velocities varying from quasi-static to $100 \mathrm{~m} / \mathrm{s}$ are considered. Ship collisions are likely to occur below $10 \mathrm{~m} / \mathrm{s}$, whereas the range from 10 to $100 \mathrm{~m} / \mathrm{s}$ is relevant to land-based transport, such as military, automotive and rail industries.

In this study, we compare and contrast the performances of two core designs: the Yframe and corrugated cores as shown in Fig. 1. To enable a fair comparison, we consider cores of identical mass and overall geometry. While numerous studies have been reported in the literature on other core topologies, such as the I-core [8], the pyramidal core [9-11] and the square honeycomb [12-16], these all use different geometries and masses thereby prohibiting us from making direct comparisons with those alternative designs.

This article is organised as follows. First, a description of the finite element model is given. Second, the dynamic indentation responses and corresponding deformation modes are presented for selected loading velocities. And third, the effects of impact velocity, indenter size and material strain-rate sensitivity upon the dynamic indentation response are explored.

\section{Description of the finite element models}

The commercial finite element code Abaqus (version 6.11) was used to simulate the quasi-static and dynamic indentation responses of sandwich panels with a corrugated core or a Y-frame core. The finite element models used in this study are based on a considerable amount of previous numerical and experimental work which demonstrated that the finite element method can accurately predict the measured response of corrugated and Y-frame sandwich structures. This was shown for a wide 
range of loading scenarios including: quasi-static [17] and dynamic [6] compression; quasi-static indentation [4,17] and three-point bending [4,5]; low-velocity impact on beams [18]; and dynamic loading of sandwich beams [19] and plates [20]. Although the current article does not include a direct comparison between experimental and numerical results for dynamic indentation, the approach used here to model the corrugated and Y-frame structures has been validated by the above previous studies.

\subsection{Dimensions of the sandwich panels}

The sandwich panels considered were assumed to be made of stainless steel (of density $\rho=7900 \mathrm{~kg} / \mathrm{m}^{3}$ ) and their dimensions were chosen to be representative of fullscale ship hulls, see Fig. 2. All panels had a half-length ${ }^{2} L=2.5 \mathrm{~m}$ and consisted of two identical face-sheets of thickness $t=6 \mathrm{~mm}$ separated by a core of depth $c=$ $0.44 \mathrm{~m}$. Both the corrugated and Y-frame cores were made from sheets of thickness $t$ $=6 \mathrm{~mm}$ and had a relative density $\bar{\rho}=2.5 \%$. Hence, the areal mass of the sandwich panel was $\bar{m}=\rho(2 t+\bar{\rho} c)=182 \mathrm{~kg} / \mathrm{m}^{2}$ in all cases. The unit cell for both types of core is of width $b=0.53 \mathrm{~m}$, as shown in Fig. 2 .

\subsection{Material properties}

The material properties were chosen to be representative of AISI 304 stainless steel. This material is representative of shipbuilding steel [5] and has been used in several studies on dynamic loading of metallic sandwich structures $[6,8,9,13-15,18-20]$. The uniaxial tensile response of type 304 stainless steel was measured by St-Pierre et al. [5] at a nominal strain-rate of $10^{-3} \mathrm{~s}^{-1}$ and is given in Fig. 3a. The response is

\footnotetext{
${ }^{2}$ Numerical experimentation showed that the half-length $L=2.5 \mathrm{~m}$ is sufficiently large to ensure that the indentation responses reported here are not dependent on $L$.
} 
characterised by a Young's modulus $E=210 \mathrm{GPa}$ and a quasi-static yield strength $\sigma_{Y}$ $=210 \mathrm{MPa}\left(\right.$ at a strain rate of $\left.10^{-3} \mathrm{~s}^{-1}\right)$.

The strain-rate sensitivity of AISI 304 stainless steel was investigated by Stout and Follansbee [21] for plastic strain-rates $\dot{\varepsilon}_{p}$ in the range $10^{-3}-10^{4} \mathrm{~s}^{-1}$. They observed that the shape of the stress versus strain response is independent of the magnitude of $\dot{\varepsilon}_{p}$, but the stress is amplified by a factor $R\left(\dot{\varepsilon}_{p}\right)$. Their results are reproduced in Fig. $3 \mathrm{~b}$, where the dynamic strengthening factor $R$ is plotted as a function of the plastic strain rate $\dot{\varepsilon}_{p}$. Consequently, the rate-dependent stress $\sigma^{d}$ versus plastic strain $\varepsilon_{p}$ response can be expressed as:

$$
\sigma^{d}\left(\varepsilon_{p}, \dot{\varepsilon}_{p}\right)=R\left(\dot{\varepsilon}_{p}\right) \sigma^{q s}\left(\varepsilon_{p}\right)
$$

where $R$ is given in Fig. $3 b$, and $\sigma^{q s}\left(\varepsilon_{p}\right)$ is taken as the measured quasi-static response (at $\dot{\varepsilon}_{p}=10^{-3} \mathrm{~s}^{-1}$ ), as shown in Fig. 3a. The influence of material strain-rate upon uniaxial response is illustrated in Fig. 3a, for four selected values of $\dot{\varepsilon}_{p}$.

The stainless steel was modelled as an elastic-plastic strain-rate dependent J2-flow theory solid with a density $\rho=7900 \mathrm{~kg} / \mathrm{m}^{3}$, Young's modulus $E=210 \mathrm{GPa}$, Poisson's ratio $v=0.3$ and quasi-static yield strength $\sigma_{Y}=210 \mathrm{MPa}$. The hardening plastic behaviour of stainless steel, for $10^{-3} \mathrm{~s}^{-1} \leq \dot{\varepsilon}_{p} \leq 10^{4} \mathrm{~s}^{-1}$, was tabulated in Abaqus based upon the above prescription and using the data shown in Fig. 3a. It is worth mentioning here that in all simulations reported subsequently, the maximum in-plane principal tensile strains were below $35 \%$. The tensile ductility of stainless steel is around 40\% (and reasonably independent of strain-rate based on Russell [22]) and thus it is unnecessary to include material failure in the constitutive description of stainless steel. 


\subsection{Boundary conditions}

The following boundary conditions were employed to simulate the dynamic indentation response of corrugated and Y-frame sandwich panels. First, all degreesof-freedom were constrained to zero on the back face of the panel, see Fig. 2. Second, symmetric boundary conditions were applied at mid-length, directly beneath the indenter $\left(x_{3}=0\right)$ and frictionless, end-clamped boundary conditions were used at the right end of the panel $\left(x_{3}=L\right)$. Finally, symmetric boundary conditions were applied on each side of the unit cell, see Fig. 2. Thus, we are considering the panel to have infinite dimension in the $x_{2}$ direction: it has the geometry of a long strip resting on a foundation.

The sandwich panels were indented using two different headshapes:

1. A flat-bottomed punch of half-width $a$, see Fig. 2a. To simplify the analysis, this loading condition was achieved by prescribing a constant velocity $V_{0}$ over a width $a$ of the front face. Two values of width were considered, $a / L=0.05$ and 0.2.

2. A rigid, circular punch of diameter $D$ indented the panel at a prescribed velocity $V_{0}$, as shown in Fig. 2b. Calculations were performed for $D / L=0.072$ and 0.528 .

The interaction between the punch and the front face, and between all potentially contacting surfaces of the sandwich panel, was modelled as a hard frictionless contact. Numerical experimentation revealed that the indentation response is relatively insensitive to the coefficient of friction used in the contact law.

The dynamic indentation response was simulated for velocities $V_{0}$ ranging from 1 to $100 \mathrm{~m} / \mathrm{s}$; these simulations were performed using the explicit solver of Abaqus. In contrast, a displacement $\delta$ was prescribed in the quasi-static indentation problem and the implicit version of Abaqus was employed. 


\subsection{Mesh and geometric imperfections}

The sandwich panels were discretised using four-noded linear shell elements with reduced integration (S4R in Abaqus notation) with an average mesh size of $10 \mathrm{~mm}$, except for the back face, which was modelled as a rigid surface (the back face does not directly influence the results but including it simplifies the post-processing such as extracting the force transmitted to the back face). A convergence study indicated that further refinement of the mesh did not improve significantly the results.

Previous laboratory investigations on corrugated and Y-frame cores revealed that geometric imperfections, with an amplitude on the order of the sheet thickness, were present in the manufactured specimens [6]. Accordingly, a geometric imperfection was introduced into both core topologies in the simulations. The imperfection had the shape of the first elastic buckling mode and the amplitude was set equal to the sheet thickness $t=6 \mathrm{~mm}$. The elastic buckling calculations were performed under uniform compression and the face-sheets were considered rigid, such that the imperfection involved only the core and not the face-sheets. The influence of the imperfection upon the dynamic indentation response is summarised in Appendix A. Therein it is demonstrated that the imperfection has only a mild effect upon the predicted response. The effect of the imperfection upon the deformed geometry quickly saturates: the deformation mode of an imperfect structure is relatively insensitive to the shape and amplitude of the imperfection.

\section{Results}

First, the dynamic indentation responses and the deformed geometries of both corrugated and Y-frame sandwich panels are presented for selected velocities. Second, the effects of the loading velocity and of the punch size upon the initial peak 
load and the average indentation load are examined. Third, the influence of material strain-rate sensitivity upon the dynamic indentation response is assessed.

\subsection{Indentation response}

The punch force versus deflection response of sandwich panels indented by (i) a flatbottomed punch of normalised width $a / L=0.05$ and (ii) a circular punch of normalised diameter $D / L=0.072$ are shown in Figs. 4 and 5, respectively. Results are given for the corrugated core in parts a, c and e of each figure and for the Y-frame core in parts $\mathrm{b}, \mathrm{d}$ and $\mathrm{f}$. The responses for the quasi-static case and for $V_{0}=1 \mathrm{~m} / \mathrm{s}$ are both shown in parts a and $\mathrm{b}$; the responses at $V_{0}=10 \mathrm{~m} / \mathrm{s}$ are given in parts $\mathrm{c}$ and $\mathrm{d}$ and those for $V_{0}=100 \mathrm{~m} / \mathrm{s}$ are in parts e and $\mathrm{f}$. In each plot, the indentation depth $\delta$ is normalised by the core thickness $c=0.44 \mathrm{~m}$, and the punch force $F$ per unit cell in the $x_{2}$ direction is normalised by $\sigma_{Y} b c$. Both the force applied to the front face and the force transmitted to the back face of the sandwich panel are plotted in each part of Figs. 4 and 5. The total back face force is the summation of the normal reaction force on all nodes of the back face.

At low velocities, $V_{0} \leq 10 \mathrm{~m} / \mathrm{s}$, the forces on the front and back faces are approximately equal, see Figs. 4a-d and 5a-d. The indentation response is characterised by an elastic regime up to an initial peak load $F_{p k}$. Subsequently, the panel softens and then re-hardens due to longitudinal stretching of the front face. The initial peak load is sensitive to core topology: sandwich panels with a corrugated core are at least $12 \%$ stronger than those with a Y-frame core.

When the velocity is increased to $100 \mathrm{~m} / \mathrm{s}$, the force on the front face largely exceeds that on the back face over the entire deformation history, see Figs. 4e,f and 5e,f. At this high velocity, the core topology has a minimal influence on the force applied to 
the front face, but it has a strong effect on the load transmitted to the back face: the force on the back face is significantly higher for the corrugated core than for the Yframe core. Note that for panels indented by a circular punch, the front-face force oscillates after impact $(\delta / c<0.1)$, see Fig. 5e,f. This is due to the fact that the punch and front face come into contact and then separate on a few occasions before a permanent contact is established. The degree of force oscillation diminishes at lower velocities; see for example the responses at $10 \mathrm{~m} / \mathrm{s}$ in Fig. $5 \mathrm{c}, \mathrm{d}$.

\subsection{Deformed geometries}

The deformed geometries corresponding to the responses shown in Figs. 4 and 5 are given in Table 1. Images are given of the deformed cross-section beneath the indenter $\left(x_{3}=0\right)$, and a side view of the sandwich panel is also displayed. All images are shown for $\delta / c=0.35$. For comparison purposes, the deformed geometries due to uniform compression are included in Table 1. All aspects of these simulations for uniform compression were identical to those detailed in Section 2, except that both cores were discretised using four-noded plane strain quadrilateral elements (CPE4R in Abaqus notation) with highly refined mesh of dimension $t / 8=0.75 \mathrm{~mm}$.

First, consider the influence of velocity on the deformation mode. The deformed geometries at 1 and $10 \mathrm{~m} / \mathrm{s}$ are very similar to those obtained quasi-statically. However, the deformed geometries at $100 \mathrm{~m} / \mathrm{s}$ differ considerably from the quasistatic results; deformation is now concentrated near the front face of the panel. This deformation mode is indicative of plastic-shock effects, with the struts folding against the front face, as observed by McShane et al [7].

Second, consider the effect of the indenter headshape upon the deformation mode. The deformation mode is insensitive to the headshape of the indenter; the deformed 
cross-sections of panels indented by a flat-bottomed punch, by a circular punch as well as those loaded under uniform compression are all very similar. These observations hold true for both corrugated and Y-frame core topologies.

\subsection{Influence of velocity on indentation load}

The effect of velocity upon the initial peak load is shown in Fig. 6a for panels indented by a flat-bottomed punch, and in Fig. 7a for panels indented by a circular punch. In both figures, the dynamic initial peak load $F_{p k}^{d}$ is normalised by the quasistatic initial peak load $F_{p k}^{q s}$. The results are plotted for velocities ranging from 1 to 30 $\mathrm{m} / \mathrm{s}$ only because it is difficult to evaluate accurately the initial peak load at higher velocities, recall the indentation responses at $100 \mathrm{~m} / \mathrm{s}$ in Fig. 5e,f.

The average load up to $\delta / c=0.2$ is defined as:

$$
F_{a v}=5 \int_{0}^{0.2} F \mathrm{~d}(\delta / c)
$$

and is plotted as a function of velocity in Figs. $6 \mathrm{~b}$ and $7 \mathrm{~b}$. In each plot, the forces on the front and back faces are included, and results for the corrugated core are compared to those of the Y-frame core.

For velocities ranging from 1 to $10 \mathrm{~m} / \mathrm{s}$, the dynamic initial peak load exceeds its quasi-static value, and increases slightly with increasing velocity due to inertia stabilisation. In line with the findings of Calladine and English [23], inertia effects are more important for the stretching-dominated corrugated core than for the bendingdominated Y-frame core, see Fig. 6a. In addition, the normalised initial peak loads of panels indented by a flat-bottomed punch (Fig. 6a) display a greater sensitivity to velocity than those indented by a circular punch (Fig. 7a). This is due to the fact that the circular punch gradually loads the structure and constitutes a more important 
loading imperfection than the flat-bottomed punch (i.e. loading itself induces an imperfection into the structure in comparison to uniform compression). This loading imperfection reduces the inertia sensitivity of the response based on the arguments presented by Calladine and English [23]. However, the loading imperfection does not affect the force equilibrium; as in the case of uniform compression [6], the peak forces on the front and back faces remain approximately equal up to 10 and $30 \mathrm{~m} / \mathrm{s}$ for the Yframe and corrugated cores, respectively. In contrast, the normalised average load $F_{a v}^{d} / F_{a v}^{q s}$ is relatively insensitive to velocity and to the choice of core topology for indentation velocities between 1 and $10 \mathrm{~m} / \mathrm{s}$.

The average force applied to the front face exceeds the force transmitted to the back face when the velocity exceeds $10 \mathrm{~m} / \mathrm{s}$, see Figs. $6 \mathrm{~b}$ and $7 \mathrm{~b}$; this is indicative of plastic-shock effects. For velocities between 10 and $100 \mathrm{~m} / \mathrm{s}$, the normalised average load on the front face increases with increasing velocity and is almost insensitive to the core topology: the force on the front face of the corrugated core is comparable to that on the Y-frame core. In contrast, the normalised average load on the back face is highly sensitive to the choice of core: the load transmitted to the back face for the corrugated core significantly exceeds that for the Y-frame core. Surprisingly, the normalised average load transmitted to the back face for the Y-frame core decreases with increasing velocity. To gain some insight into this observation, the traction distribution on the back face was evaluated. For an indentation depth $\delta / c=0.2$, it was found that a tensile traction exists between the Y-frame core and back face, approximately $0.003 \sigma_{Y}$ in magnitude, over a portion $0.7 \leq x_{3} / L \leq 1$ for $V_{0}=50 \mathrm{~m} / \mathrm{s}$, and over $0.5 \leq x_{3} / L \leq 1$ when $V_{0}=100 \mathrm{~m} / \mathrm{s}$. This zone of tensile traction increases with increasing $V_{0}$, and leads to a reduction in the back face force. 


\subsection{Influence of indenter size upon indentation load}

The effect of indenter size on the normalised initial peak load and on the normalised average load is shown in Fig. 8 for panels indented by a flat-bottomed punch and in Fig. 9 for panels indented by a circular punch. In each figure, the normalised initial peak loads are shown in parts a and b for the corrugated core and the Y-frame core, respectively. Likewise, the normalised average loads are given in part $\mathrm{c}$ for the corrugated core and in part $\mathrm{d}$ for the $\mathrm{Y}$-frame core. In each plot, results for uniform compression are included; these correspond to the limiting case of an infinitely large indenter $(a / L=1$ for a flat-bottomed punch and $D / L \rightarrow \infty$ for a circular punch).

It is clear from Figs. 8 and 9 that the values of $F_{p k}^{d} / F_{p k}^{q s}$ and $F_{a v}^{d} / F_{a v}^{q s}$ for uniform compression exceed those obtained for indentation: local indentation acts in a similar manner to an imperfection in the buckling response of the core. The width of the flatbottomed punch has a strong influence on the normalised initial peak load: upon increasing $a / L$ from 0.05 to $0.20, F_{p k}^{d} / F_{p k}^{q s}$ increases by a factor of approximately two for both the corrugated core and the Y-frame core. In contrast, the diameter of the circular punch has only a mild effect on the normalised initial peak loads: upon increasing $D / L$ from 0.072 to $0.528, F_{p k}^{d} / F_{p k}^{q s}$ increases by up to $45 \%$.

We further note from Figs. 8 and 9 that the average load applied to the front face exceeds the average load transmitted to the back face at velocities above $10 \mathrm{~m} / \mathrm{s}$ in all cases considered. Hence, the velocity at which plastic-shock effects in the core become significant is relatively insensitive to the size and shape of the indenter.

\subsection{Influence of material strain-rate sensitivity}

In all simulations reported above, the stainless steel was modelled as a rate-dependent solid, as detailed in Section 2.2. Here, we complete our study by assessing the effect 
of material strain-rate sensitivity upon the dynamic indentation response. Additional simulations were conducted in which the stainless steel was modelled as a rateindependent solid; the uniaxial tensile response of the material was tabulated from the quasi-static $\left(10^{-3} \mathrm{~s}^{-1}\right)$ response as plotted in Fig. 3a. All other aspects of the simulations were identical to those used previously, see Section 2.

The influence of strain-rate sensitivity is shown in Fig. 10 for sandwich panels indented by a circular punch $D / L=0.072$. Results for a rate-independent material are compared to those obtained previously for a rate-dependent solid. The normalised peak and average loads are given in Fig. 10a and b, respectively. Each plot includes results for both corrugated and Y-frame cores, but, for the sake of brevity, only the force applied on the front face is given.

The results in Fig. 10 indicate that material strain-rate sensitivity has a relatively small effect on the dynamic indentation loads. In fact, by neglecting material strain-rate sensitivity the peak and average loads on the front face decrease by approximately $15 \%$ in the range $1 \mathrm{~m} / \mathrm{s} \leq V_{0} \leq 100 \mathrm{~m} / \mathrm{s}$, for both core topologies. Previous studies $[6,7]$ showed that material strain-rate sensitivity has a negligible effect on the dynamic compressive response of corrugated and Y-frame cores. The results in Fig. 10 suggest that this also holds true when the loading conditions are changed from uniform compression to localised indentation.

\section{Concluding remarks}

The finite element method was used to investigate the dynamic indentation response of stainless steel sandwich panels with a corrugated core or a Y-frame core. The panels were indented at a constant velocity ranging from quasi-static loading to 100 
$\mathrm{m} / \mathrm{s}$, and two different headshapes were considered: flat-bottomed and circular punches.

The deformation mode of the sandwich panel was sensitive to impact velocity, but relatively insensitive to the headshape and size of the indenter. The indentation force applied to the front face of the panel was equal to the force transmitted to the back face for velocities below $10 \mathrm{~m} / \mathrm{s}$. At these low velocities, inertia stabilisation effects increased the dynamic initial peak load above its quasi-static value, and this effect was more important for the corrugated core than for the Y-frame core. This strengthening was greater for the flat-bottomed punch than for the circular punch, and also increased with the size of the indenter.

At velocities above $10 \mathrm{~m} / \mathrm{s}$, the force applied to the front face exceeded the force transmitted to the back face due to plastic-shock effects. The force applied to the front face was comparable for both core topologies; however, the force transmitted to the back face was significantly less for panels with a Y-frame core than for those with a corrugated core. This result is independent of the size and shape of indenter, and demonstrates the advantage of the Y-frame core over the corrugated the core in protecting the underlying structure in the event of a collision.

\section{Acknowledgments}

This research was carried out under the project number MC2.06261 in the framework of the Research Program of the Materials innovation institute M2i (www.m2i.nl). The authors are also grateful for the financial support of the Fonds Québécois de la Recherche sur la Nature et les Technologies (FQRNT). 


\section{Appendix A: Influence of geometric imperfections}

The sensitivity of dynamic indentation response to the shape and amplitude of a geometric imperfection is explored in this appendix. The shape of the imperfection is obtained by superimposing one or multiple elastic buckling modes. The effect of the number of superimposed modes and their amplitude is addressed below for sandwich panels indented by a circular punch with $D / L=0.072$ and $V_{0}=10 \mathrm{~m} / \mathrm{s}$.

\section{A.1. Influence of the number of superimposed modes}

The effect of the number of superimposed elastic eigenmodes upon the dynamic indentation response at $V_{0}=10 \mathrm{~m} / \mathrm{s}$ is shown in Fig. A.1a and b for the corrugated core and the Y-frame core, respectively. For each core, three cases are compared: (i) a perfect structure (no imperfection), (ii) an imperfection with an amplitude $\zeta=t=$ $6 \mathrm{~mm}$ in the shape of the first buckling mode and (iii) an imperfection with $\zeta=t=$ $6 \mathrm{~mm}$ in the form of the first five buckling modes superimposed (each mode is ascribed the same amplitude). For both core topologies, the results indicate that the number of superimposed modes has a negligible effect on the initial peak load and only a mild influence on the post-peak response. A geometric imperfection in the shape of the first buckling mode is assumed in the body of the paper.

\section{A.2. Influence of amplitude}

The effect of imperfection amplitude upon the dynamic indentation response at $V_{0}=$ $10 \mathrm{~m} / \mathrm{s}$ is given in Fig. A.2a for the corrugated core and in Fig. A.2b for the Y-frame core. In each plot, results are compared for a perfect structure (no imperfection) and for an imperfection in the form of the first buckling mode with three different amplitudes $\zeta=3,6$ and $12 \mathrm{~mm}$ (corresponding to $0.5 t, t$ and $2 t$, respectively). The predictions show that the initial peak load is insensitive to the imperfection amplitude; however, the post-peak response slightly softens with increasing $\zeta$. Previously, Tilbrook et al. [6] found that an assumed geometric imperfection of amplitude equal 
to the sheet thickness gave good agreement with the observed collapse response of corrugated and Y-frame. Accordingly, an imperfection amplitude $\zeta=t=6 \mathrm{~mm}$ was employed in the body of the current paper.

\section{A.3. Influence of imperfection upon the deformed geometry}

The deformed geometries corresponding to the responses shown in Figs. A.1 and A.2 are given in Table A.1. The images show the deformed cross-section of the panel beneath the circular punch $\left(x_{3}=0\right)$ at an indentation depth $\delta / c=0.35$. The deformed geometry is somewhat imperfection-sensitive. However, the effect of the imperfection quickly saturates: the deformed geometry of an imperfect sandwich panel is relatively insensitive to the shape and amplitude of the imperfection. 


\section{References}

[1] Kujala P, Hänninen M, Arola T, Ylitalo J. Analysis of the marine traffic safety in the Gulf of Finland. Reliab Eng Syst Safe 2009;94:1349-57.

[2] Naar H, Kujala P, Simonsen BC, Ludolphy H. Comparison of the crashworthiness of various bottom and side structures. Mar Struct 2002;15:44360.

[3] Wevers LJ, Vredeveldt AW. Full scale ship collision experiments 1998. TNO technical report No. 98-CMC-R1725. Delft; 1999.

[4] Rubino V, Deshpande VS, Fleck NA. The three-point bending of the Y-frame and corrugated core sandwich beams. Int J Mech Sci 2010;52:485-94.

[5] St-Pierre L, Fleck NA, Deshpande VS. Sandwich beams with corrugated and Yframe cores: does the back face contribute to the bending response? J Appl Mech 2012;79:011002.

[6] Tilbrook MT, Radford DD, Deshpande VS, Fleck NA. Dynamic crushing of sandwich panels with prismatic lattice cores. Int J Solids Struct 2007;44:610323.

[7] McShane GJ, Pingle SM, Deshpande VS, Fleck NA. Dynamic buckling of an inclined strut. Int J Solids Struct 2012;49:2830-8.

[8] Ferri E, Antinucci E, He MY, Hutchinson JW, Zok FW, Evans AG. Dynamic buckling of impulsively loaded prismatic cores. J Mech Mater Struct 2006; 1:1345-65.

[9] Lee S, Barthelat F, Hutchinson JW, Espinosa HD. Dynamic failure of metallic pyramidal truss core materials - Experiments and modeling. Int J Plast 2006;22:2118-45.

[10] Dharmasena KP, Wadley HNG, Williams K, Xue Z, Hutchinson JW. Response of metallic pyramidal lattice core sandwich panels to high intensity impulsive loading in air. Int J Impact Eng 2011;38:275-89. 
[11] Radford DD, Fleck NA, Deshpande VS. The response of clamped sandwich beams subjected to shock loading. Int J Impact Eng 2006;32:968-87.

[12] Xue Z, Hutchinson JW. Crush dynamics of square honeycomb sandwich cores. Int J Numer Meth Eng 2006;65:2221-45.

[13] Radford DD, McShane GJ, Deshpande VS, Fleck NA. Dynamic compressive response of stainless-steel square honeycombs. J Appl Mech 2007;74:658-67.

[14] Mcshane GJ, Radford DD, Deshpande VS, Fleck NA. The response of clamped sandwich plates with lattice cores subjected to shock loading. Eur J Mech A/Solids 2006;25:215-29.

[15] Rathbun HJ, Radford DD, Xue Z, He MY, Yang J, Deshpande VS, et al. Performance of metallic honeycomb-core sandwich beams under shock loading. Int J Solids Struct 2006;43:1746-63.

[16] Dharmasena KP, Wadley HNG, Xue Z, Hutchinson JW. Mechanical response of metallic honeycomb sandwich panel structures to high-intensity dynamic loading. Int J Impact Eng 2008;35:1063-74.

[17] Rubino V, Deshpande VS, Fleck NA. The collapse response of sandwich beams with a Y-frame core subjected to distributed and local loading. Int J Mech Sci 2008;50:233-46.

[18] St-Pierre L, Deshpande VS, Fleck NA. The low velocity impact response of sandwich beams with a corrugated core or a Y-frame core. Int J Mech Sci, in press. http://dx.doi.org/10.1016/j.ijmecsci.2014.02.014

[19] Rubino V, Deshpande VS, Fleck NA. The dynamic response of end-clamped sandwich beams with a Y-frame or corrugated core. Int J Impact Eng 2008;35:829-44.

[20] Rubino V, Deshpande VS, Fleck NA. The dynamic response of clamped rectangular Y-frame and corrugated core sandwich plates. Eur J Mech A/Solids 2009;28:14-24. 
[21] Stout MG, Follansbee PS. Strain-rate sensitivity, strain-hardening, and yield behaviour of 304L stainless steel. J Eng Mater Technol 1986;108:344-53.

[22] Russell BP. Multi-hit ballistic damage characterisation of 304 stainless steel plates with finite elements. Mater Design 2014;58:252-64.

[23] Calladine CR, English RW. Strain-rate and inertia effects in the collapse of two types of energy-absorbing structure. Int J Mech Sci 1984;26:689-701. 


\section{Table captions}

Table 1. Comparison between the deformed geometries of corrugated and Y-frame sandwich panels under three loading conditions: uniform compression, indentation by a flat-bottomed punch of normalised width $a / L=0.05$ and indentation by a circular punch of normalised diameter $D / L=0.072$. Results are shown at selected velocities. For indentation, the cross-section underneath the punch is shown along with a side view of the panel. All images are given for $\delta / c=0.35$.

Table A.1. Influence of a geometric imperfection upon the deformed geometry of sandwich panels indented by a circular punch of normalised diameter $D / L=0.072$ at $V_{0}=10 \mathrm{~m} / \mathrm{s}$. The images show the cross-section of the panel underneath the punch. Results are given for corrugated and Y-frame cores at $\delta / c=0.35$.

\section{Figure captions}

Fig. 1. Sandwich hull designs with (a) a Y-frame core and (b) a corrugated core.

Fig. 2. Dimensions and boundary conditions of (a) a sandwich panel with a corrugated core indented by a flat-bottomed punch and (b) a sandwich panel with a Yframe core indented by a circular punch. All dimensions are in $\mathrm{mm}$.

Fig. 3. (a) The measured quasi-static $\left(\dot{\varepsilon}_{p}=10^{-3} \mathrm{~s}^{-1}\right)$ uniaxial tensile response of AISI 304 stainless steel and the estimated high strain-rate responses based on the data of Stout and Follansbee [21]. (b) Dynamic strengthening factor $R$ as a function of plastic strain rate $\dot{\varepsilon}_{p}$.

Fig. 4. Responses of sandwich panels indented by a flat-bottomed punch of normalised width $a / L=0.05$. Results are shown at selected velocities: quasi-static and $1 \mathrm{~m} / \mathrm{s}$ for (a) corrugated core and (b) Y-frame core; $10 \mathrm{~m} / \mathrm{s}$ for (c) corrugated core and (d) Y-frame core and $100 \mathrm{~m} / \mathrm{s}$ for (e) corrugated core and (f) $\mathrm{Y}$-frame core.

Fig. 5. Responses of sandwich panels indented by a circular punch of normalised diameter $D / L=0.072$. Results are shown at selected velocities: quasi-static and $1 \mathrm{~m} / \mathrm{s}$ for (a) corrugated core and (b) Y-frame core; $10 \mathrm{~m} / \mathrm{s}$ for (c) corrugated core and (d) Y-frame core and $100 \mathrm{~m} / \mathrm{s}$ for (e) corrugated core and (f) Y-frame core. 
Fig. 6. (a) The normalised initial peak load and (b) the normalised average load up to $\delta / c=0.2$ for corrugated and Y-frame sandwich panels indented at a constant velocity $V_{0}$ by a flat-bottomed punch of normalised width $a / L=0.05$.

Fig. 7. (a) The normalised initial peak load and (b) the normalised average load up to $\delta / c=0.2$ for corrugated and Y-frame sandwich panels indented at a constant velocity $V_{0}$ by a circular punch of normalised diameter $D / L=0.072$.

Fig. 8. Influence of the normalised width $a / L$ of the flat-bottomed punch on the normalised initial peak load for (a) the corrugated core and (b) the Y-frame core. Likewise, the influence of $a / L$ on the normalised average load up to $\delta / c=0.2$ is shown for (c) the corrugated core and (d) the Y-frame core.

Fig. 9. Influence of the normalised diameter $D / L$ of the circular punch on the normalised initial peak load for (a) the corrugated core and (b) the Y-frame core. Likewise, the influence of $D / L$ on the normalised average load up to $\delta / c=0.2$ is shown for (c) the corrugated core and (d) the Y-frame core.

Fig. 10. Influence of material strain-rate sensitivity on (a) the normalised initial peak load and (b) the normalised average load up to $\delta / c=0.2$. Results are shown for sandwich panels with a corrugated core or a Y-frame core indented by a circular punch of normalised diameter $D / L=0.072$, and only the force applied on the front face is shown.

Fig. A.1. Influence of imperfection shape upon the response of sandwich panels indented by a circular punch of normalised diameter $D / L=0.072$ at $V_{0}=10 \mathrm{~m} / \mathrm{s}$. In all cases, the imperfection amplitude is $\zeta=t=6 \mathrm{~mm}$. The force on the front face is shown for (a) corrugated core and (b) Y-frame core.

Fig. A.2. Influence of imperfection amplitude upon the response of sandwich panels indented by a circular punch of normalised diameter $D / L=0.072$ at $V_{0}=10 \mathrm{~m} / \mathrm{s}$. In all cases, the imperfection shape is in the form of the first buckling mode. The force on the front face is shown for (a) corrugated core and (b) Y-frame core. 
(a)

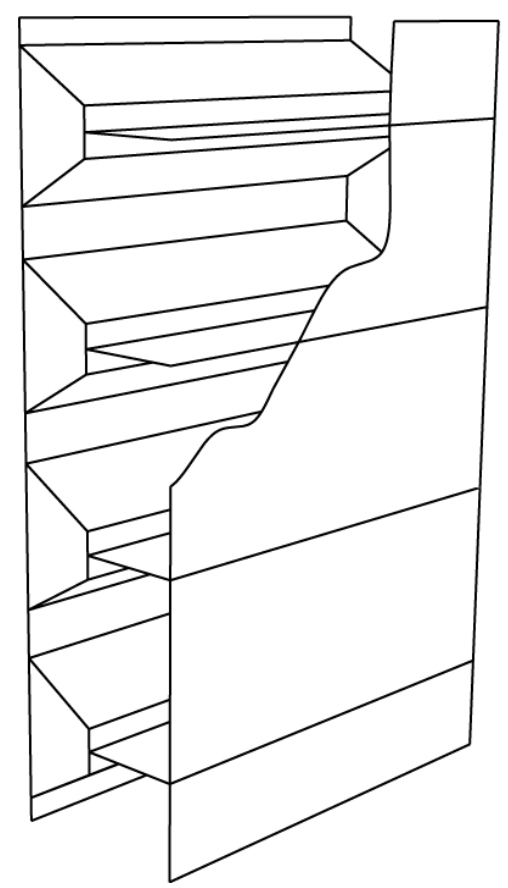

(b)

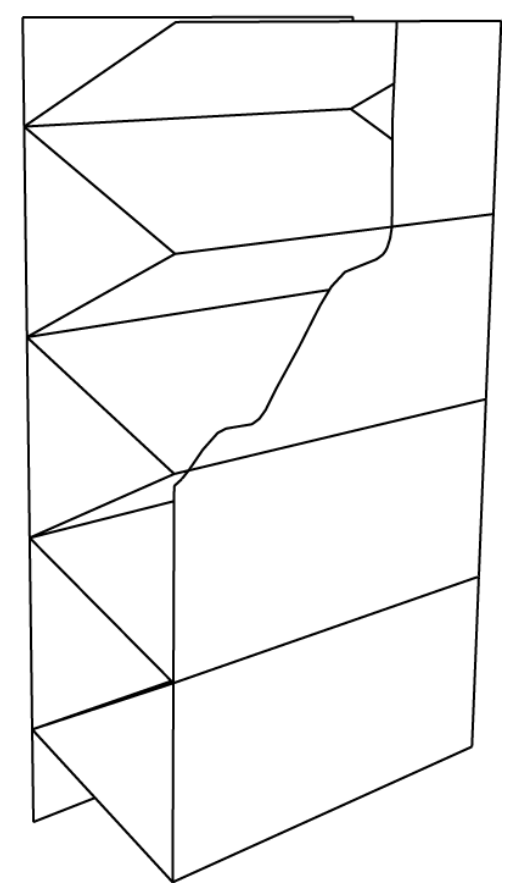

Fig. 1. Sandwich hull designs with (a) a Y-frame core and (b) a corrugated core. 
(a)
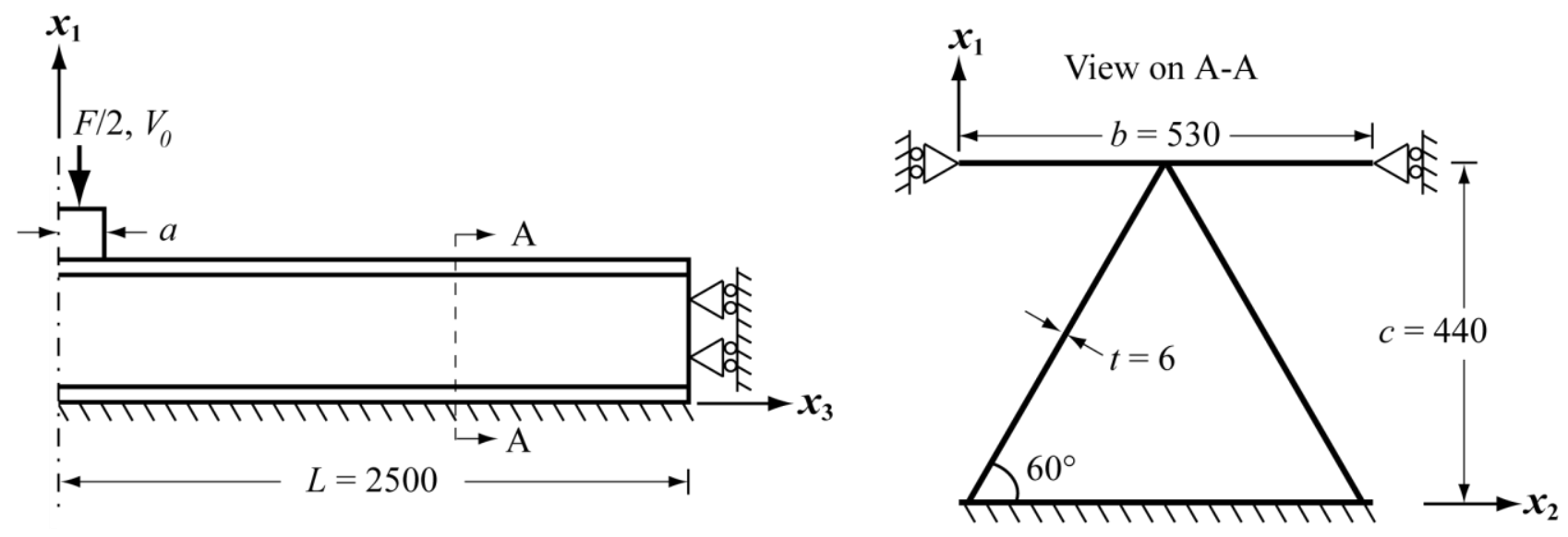

(b)
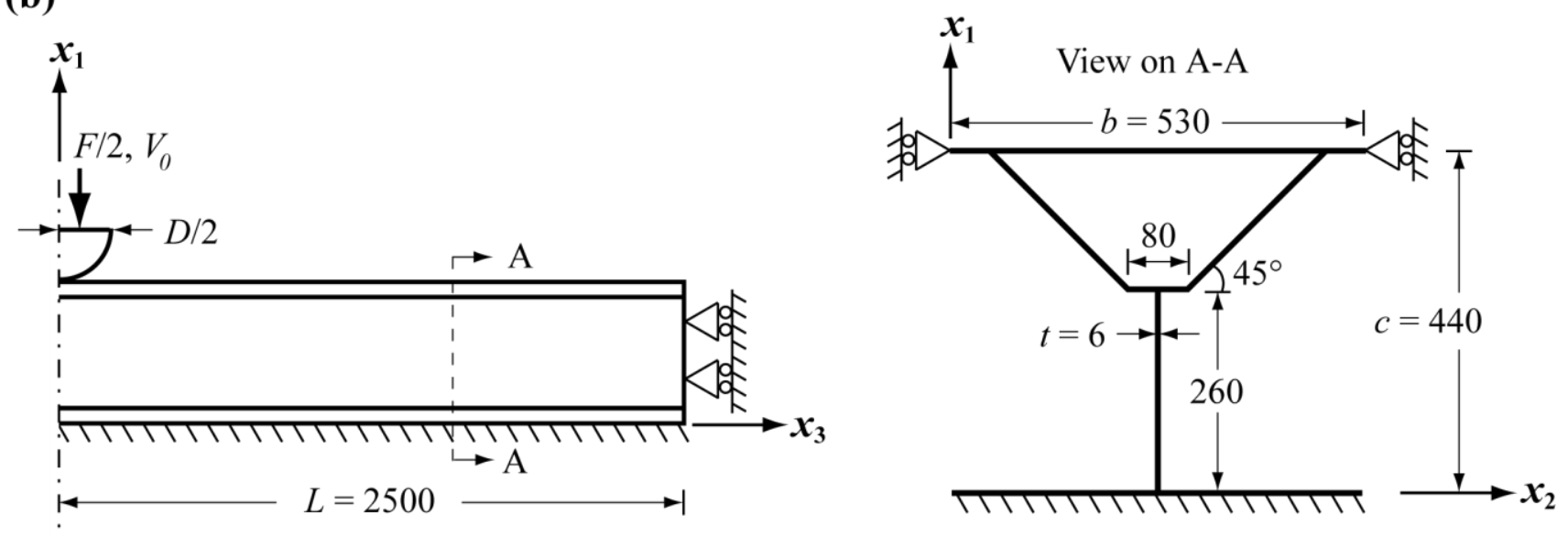

Fig. 2. Dimensions and boundary conditions of (a) a sandwich panel with a corrugated core indented by a flat-bottomed punch and (b) a sandwich panel with a Y-frame core indented by a circular punch. All dimensions are in $\mathrm{mm}$. 
(a)

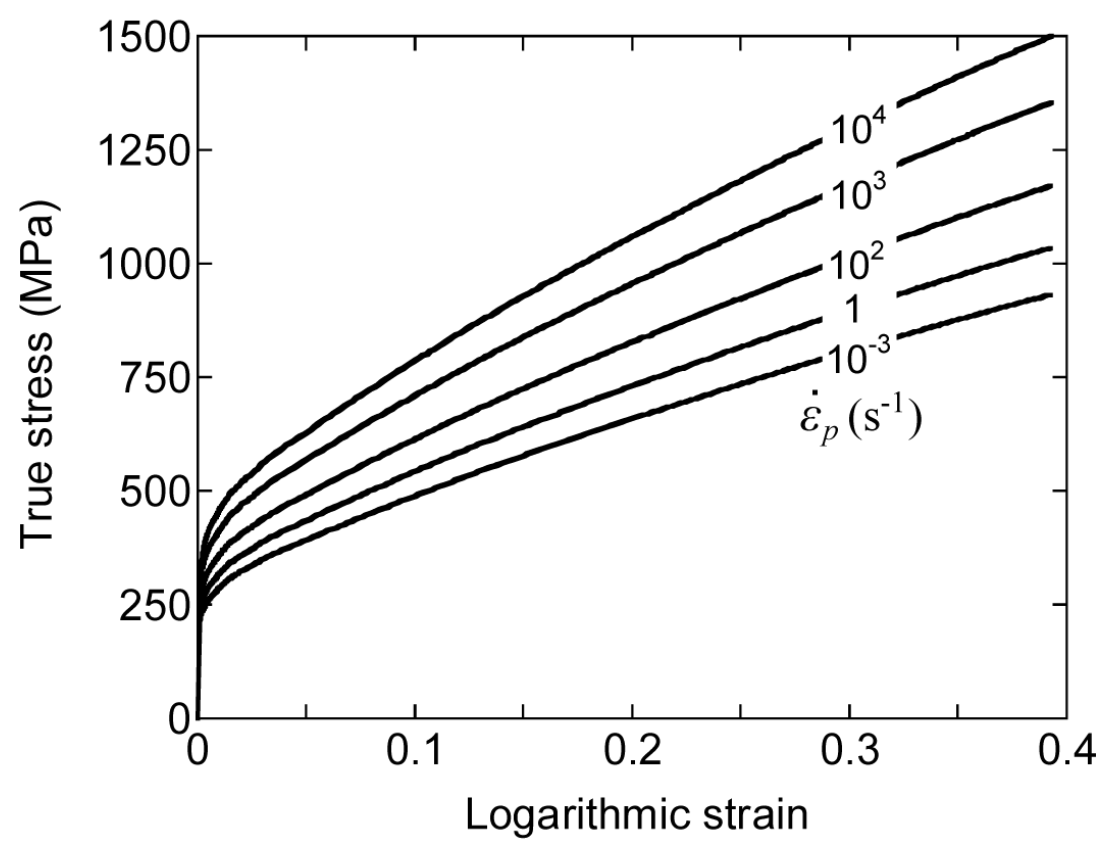

(b)

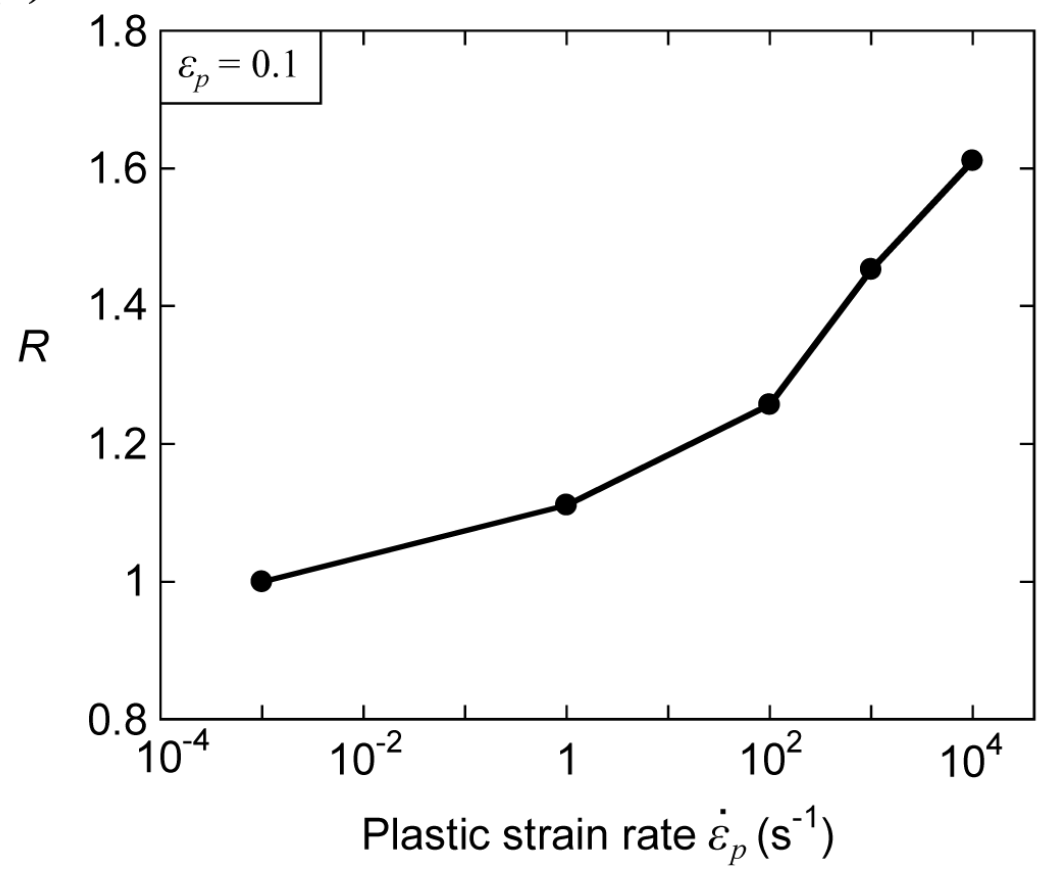

Fig. 3. (a) The measured quasi-static $\left(\dot{\varepsilon}_{p}=10^{-3} \mathrm{~s}^{-1}\right)$ uniaxial tensile response of AISI 304 stainless steel and the estimated high strain-rate responses based on the data of Stout and Follansbee [21]. (b) Dynamic strengthening factor $R$ as a function of plastic strain rate $\dot{\varepsilon}_{p}$. 

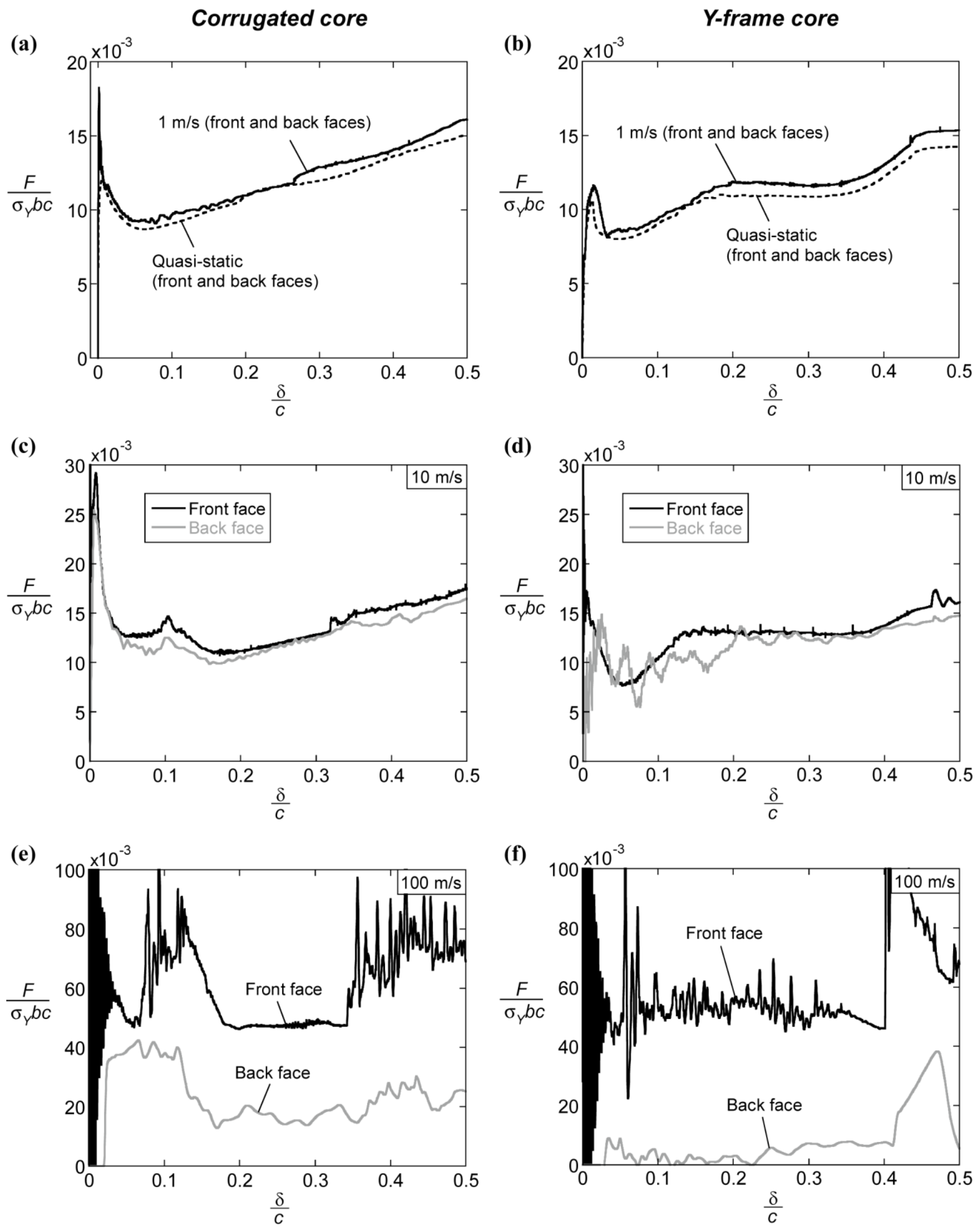

Fig. 4. Responses of sandwich panels indented by a flat-bottomed punch of normalised width $a / L=$ 0.05. Results are shown at selected velocities: quasi-static and $1 \mathrm{~m} / \mathrm{s}$ for (a) corrugated core and (b) Y-frame core; $10 \mathrm{~m} / \mathrm{s}$ for (c) corrugated core and (d) Y-frame core and $100 \mathrm{~m} / \mathrm{s}$ for (e) corrugated core and (f) Y-frame core. 
(a)

\section{Corrugated core}

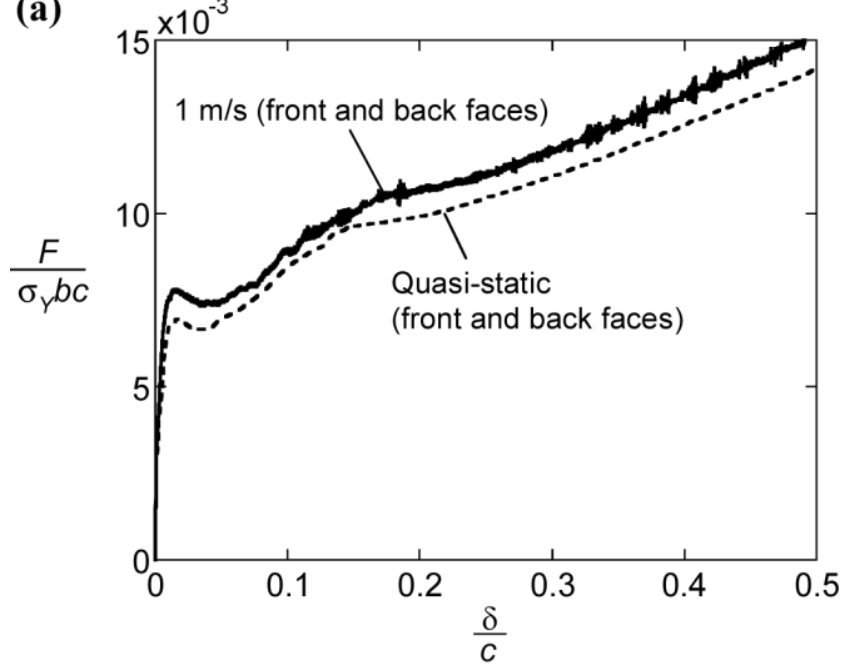

(c)
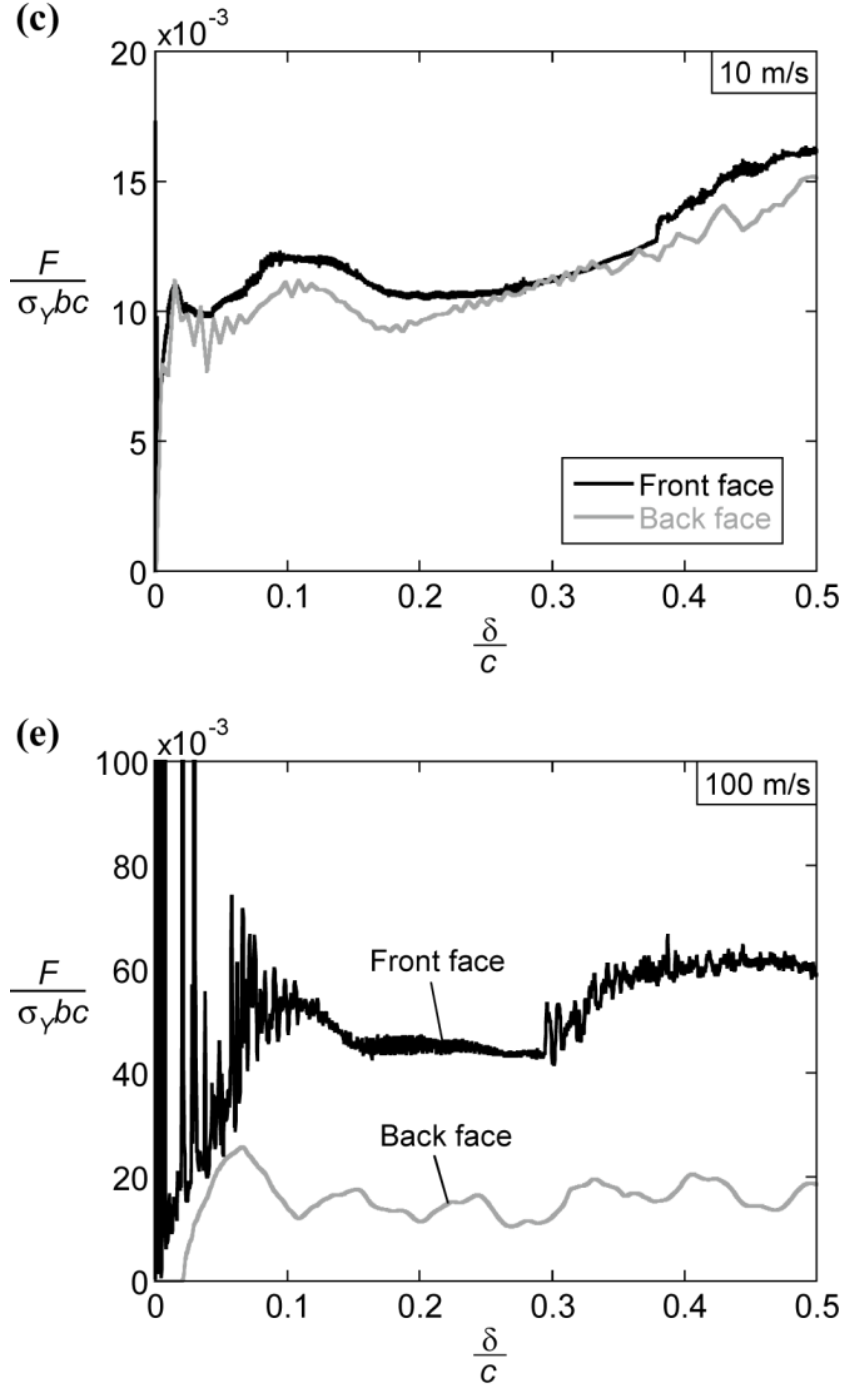

(b)

Y-frame core
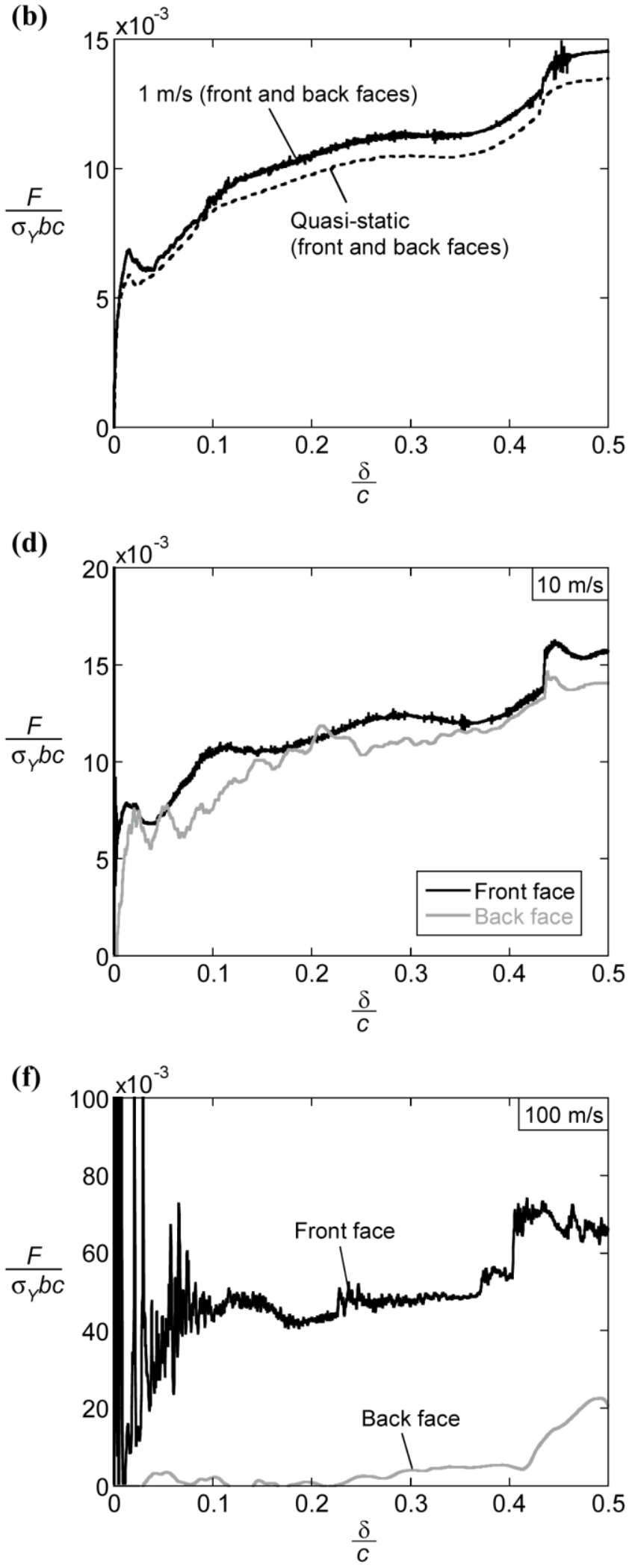

Fig. 5. Responses of sandwich panels indented by a circular punch of normalised diameter $D / L=$ 0.072. Results are shown at selected velocities: quasi-static and $1 \mathrm{~m} / \mathrm{s}$ for (a) corrugated core and (b) Y-frame core; $10 \mathrm{~m} / \mathrm{s}$ for (c) corrugated core and (d) Y-frame core and $100 \mathrm{~m} / \mathrm{s}$ for (e) corrugated core and (f) Y-frame core. 


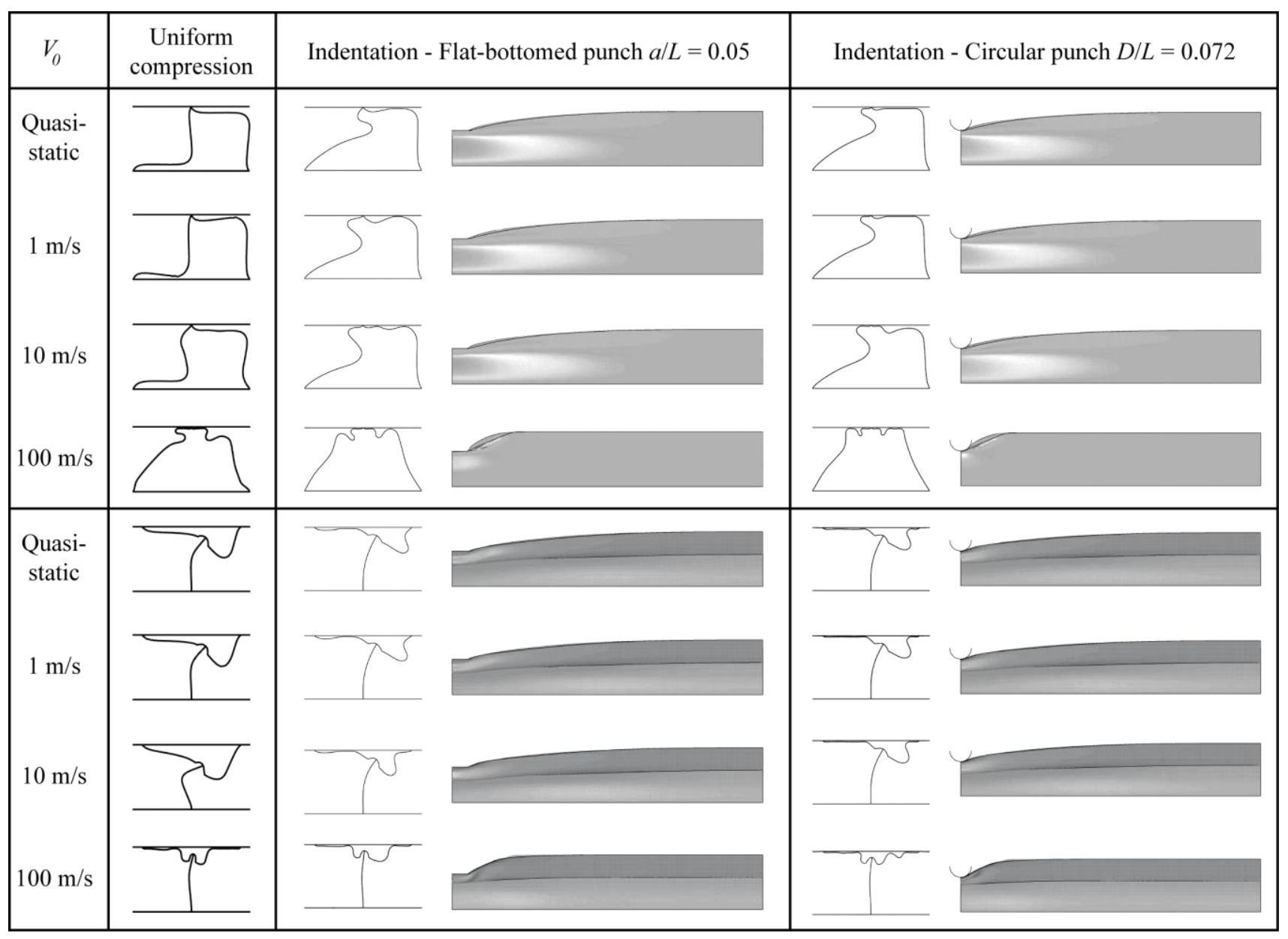

Table 1. Comparison between the deformed geometries of corrugated and Y-frame sandwich panels under three loading conditions: uniform compression, indentation by a flat-bottomed punch of normalised width $a / L=0.05$ and indentation by a circular punch of normalised diameter $D / L=$ 0.072. Results are shown at selected velocities. For indentation, the cross-section underneath the punch is shown along with a side view of the panel. All images are given for $\delta / c=0.35$. 
(a)

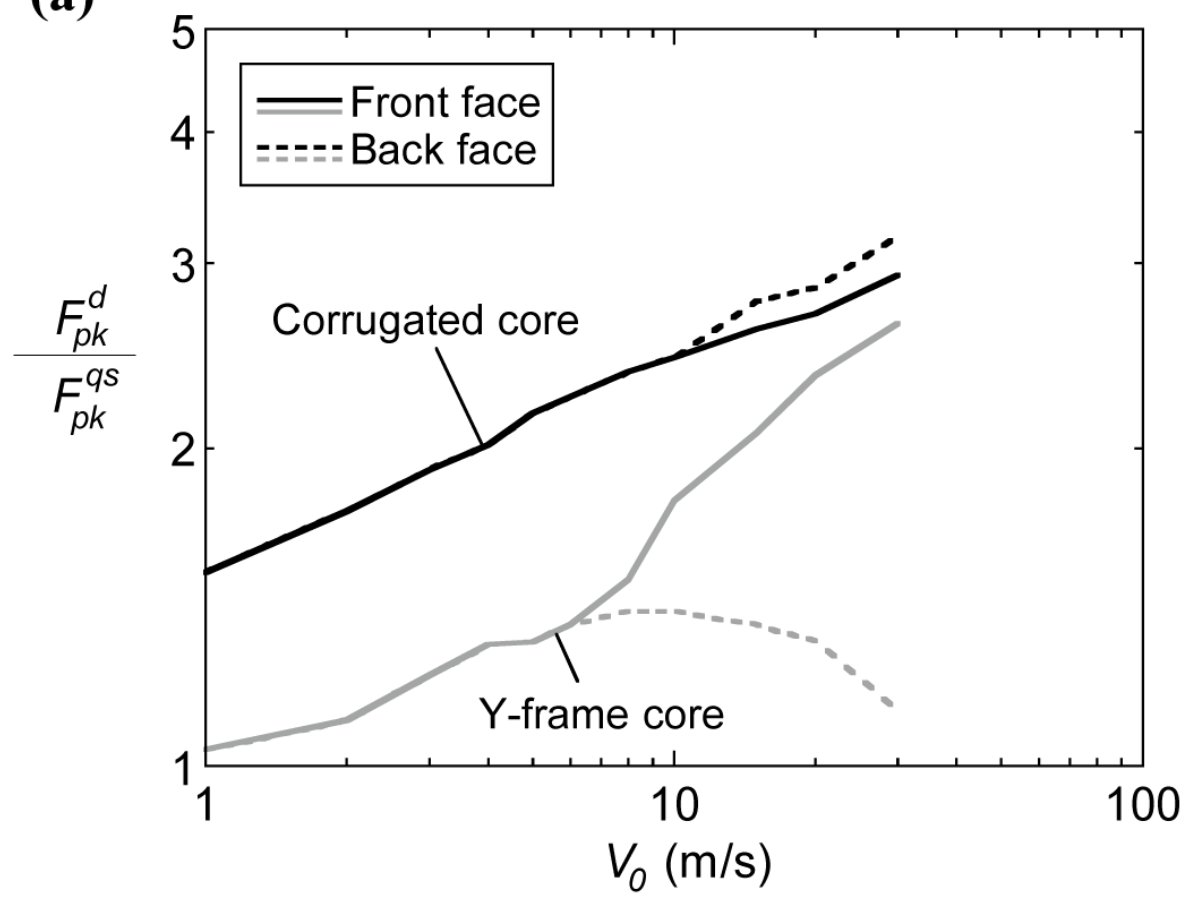

(b)

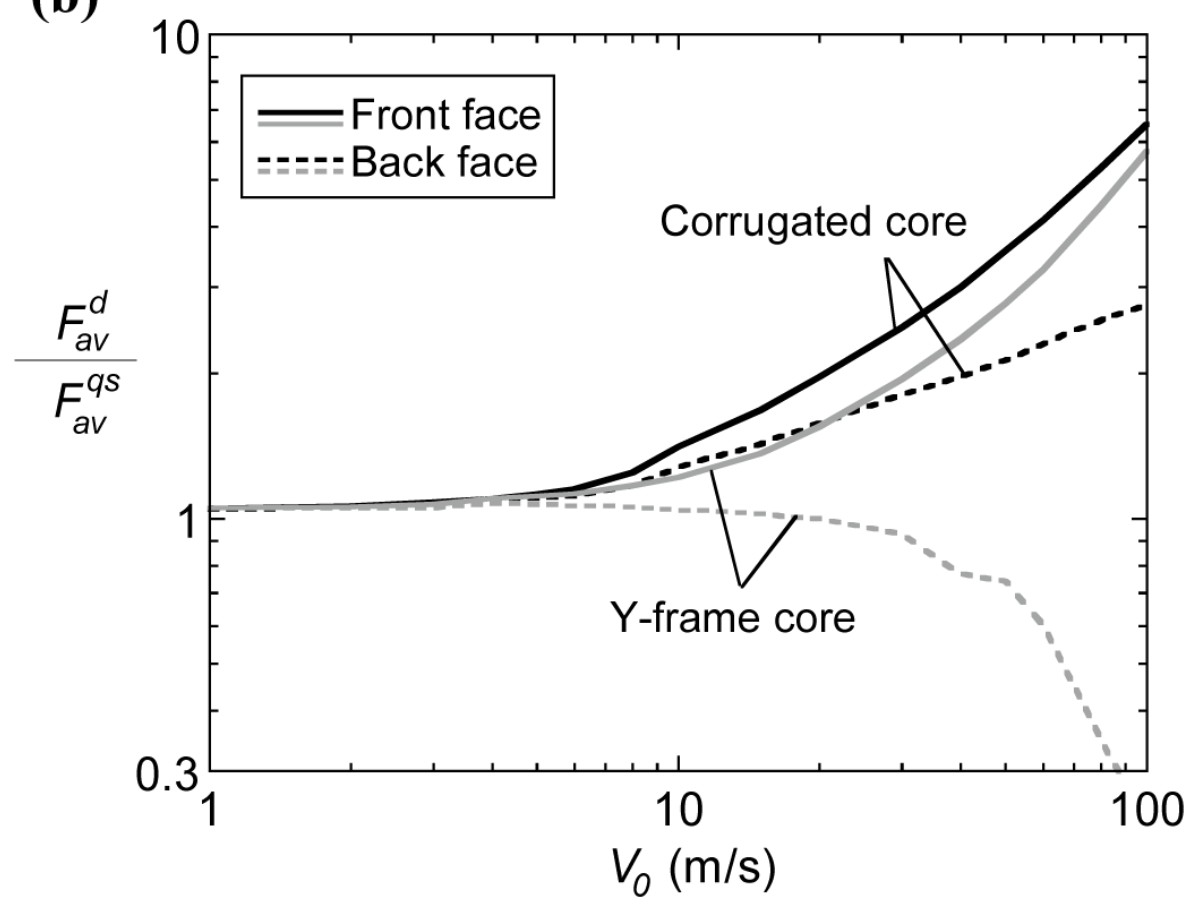

Fig. 6. (a) The normalised initial peak load and (b) the normalised average load up to $\delta / c=0.2$ for corrugated and Y-frame sandwich panels indented at a constant velocity $V_{O}$ by a flat-bottomed punch of normalised width $a / L=0.05$. 
(a)

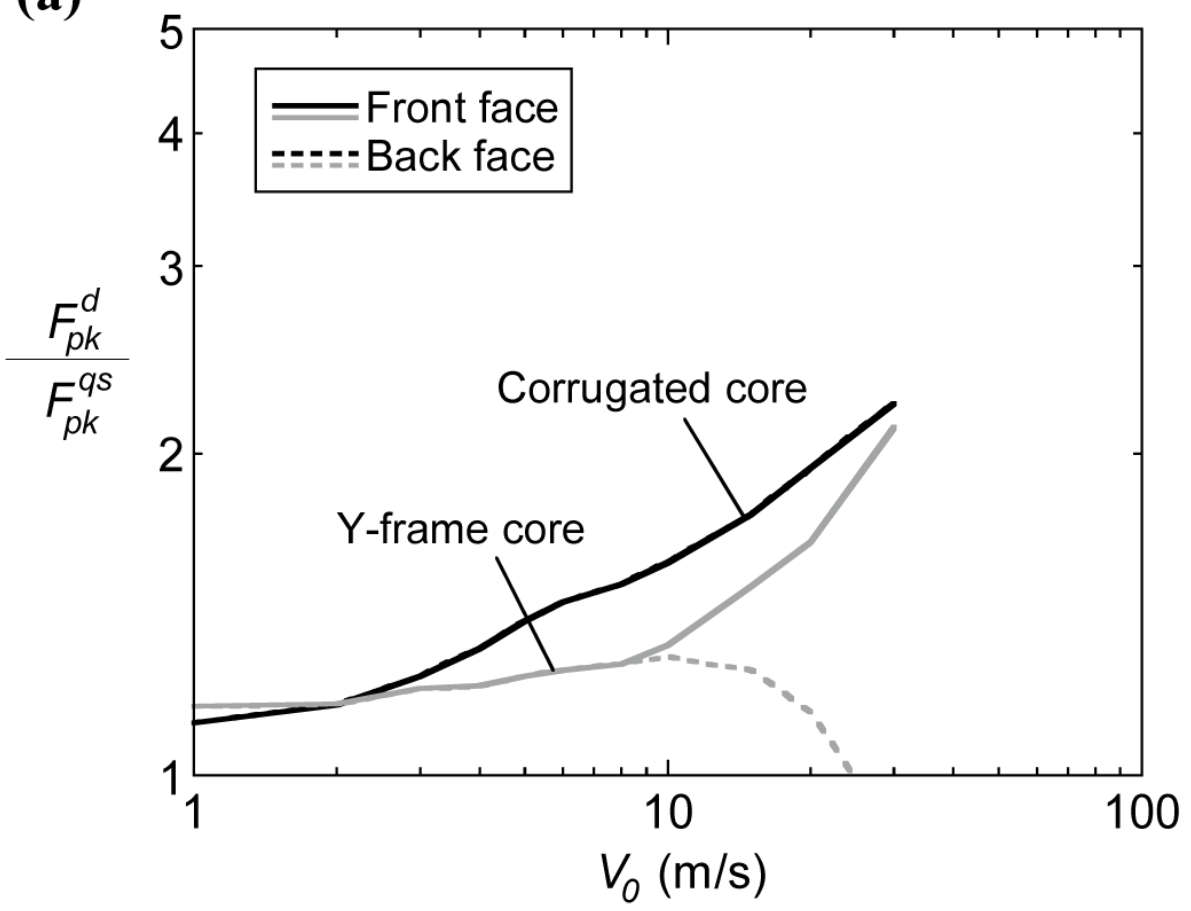

(b)

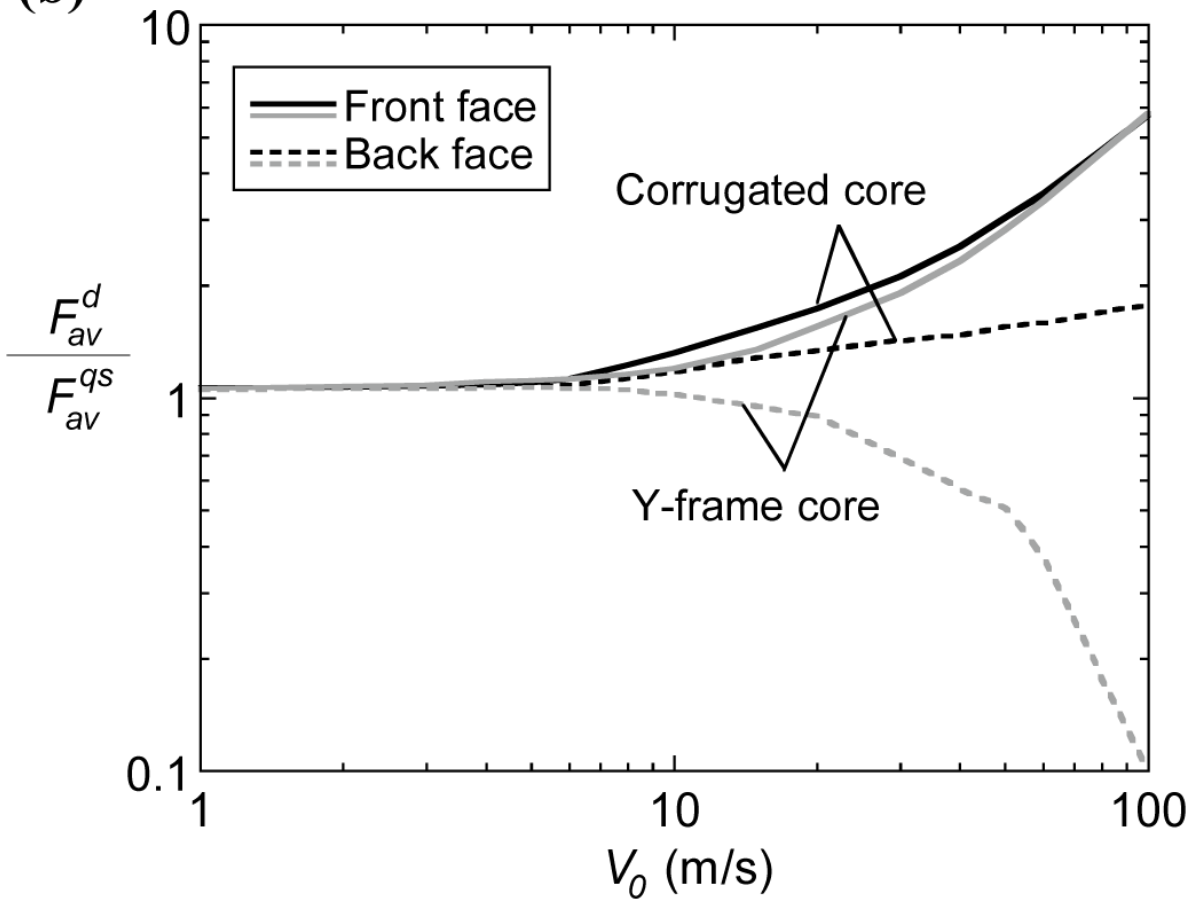

Fig. 7. (a) The normalised initial peak load and (b) the normalised average load up to $\delta / c=0.2$ for corrugated and Y-frame sandwich panels indented at a constant velocity $V_{0}$ by a circular punch of normalised diameter $D / L=0.072$. 
Corrugated core

(a)

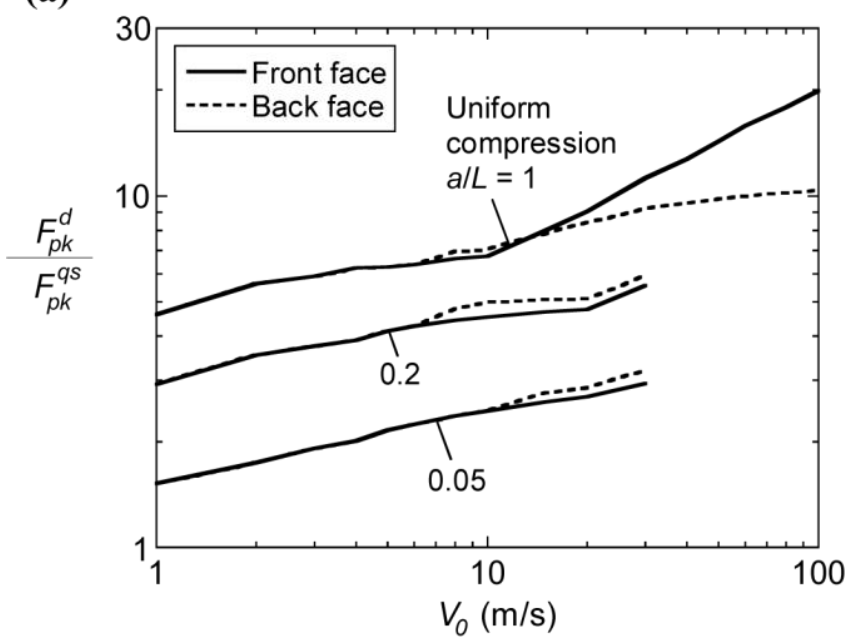

(c)

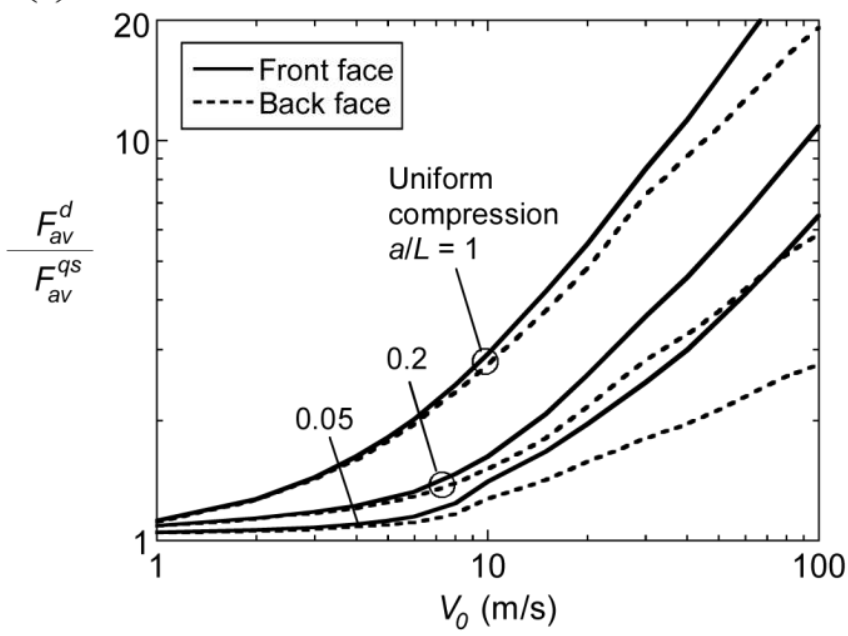

Y-frame core

(b)

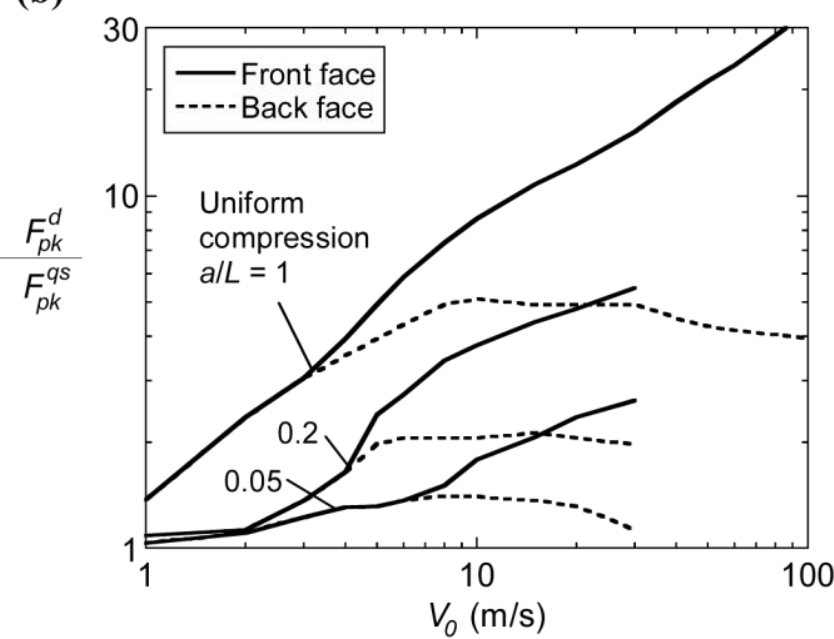

(d)

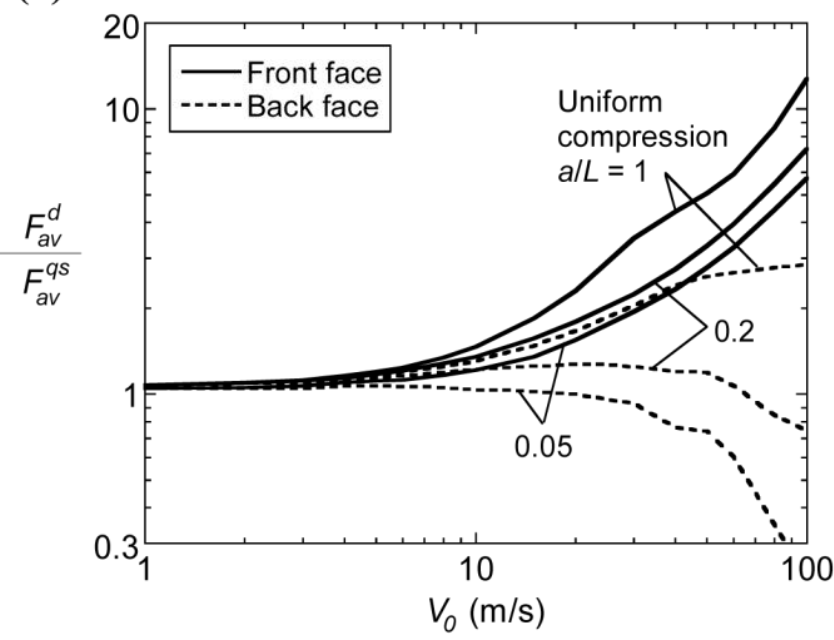

Fig. 8. Influence of the normalised width $a / L$ of the flat-bottomed punch on the normalised initial peak load for (a) the corrugated core and (b) the Y-frame core. Likewise, the influence of $a / L$ on the normalised average load up to $\delta / c=0.2$ is shown for (c) the corrugated core and (d) the Y-frame core. 
Corrugated core

(a)

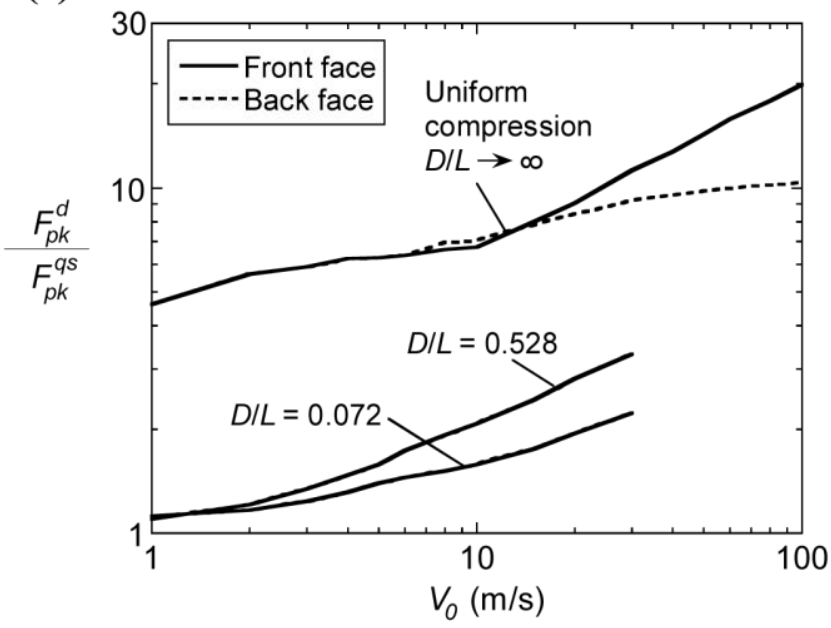

(c)

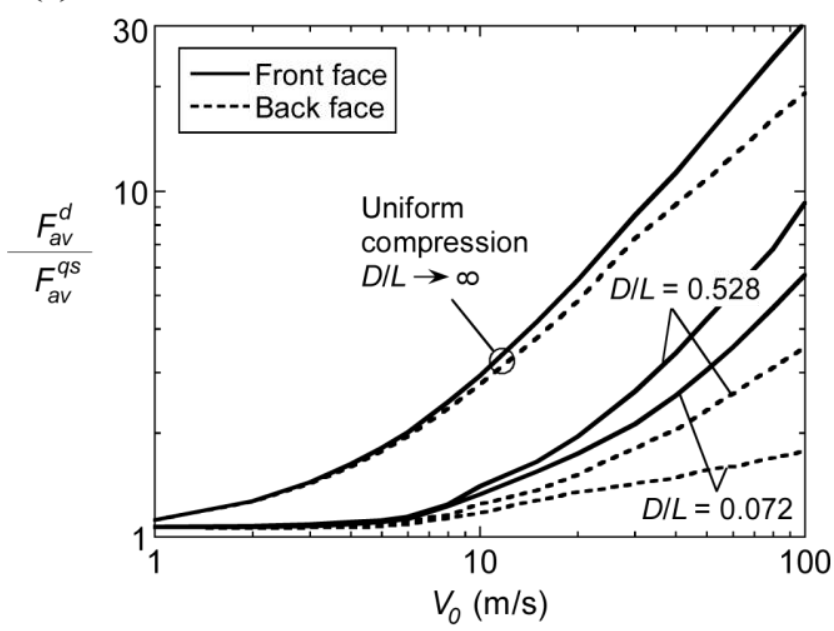

Y-frame core

(b)

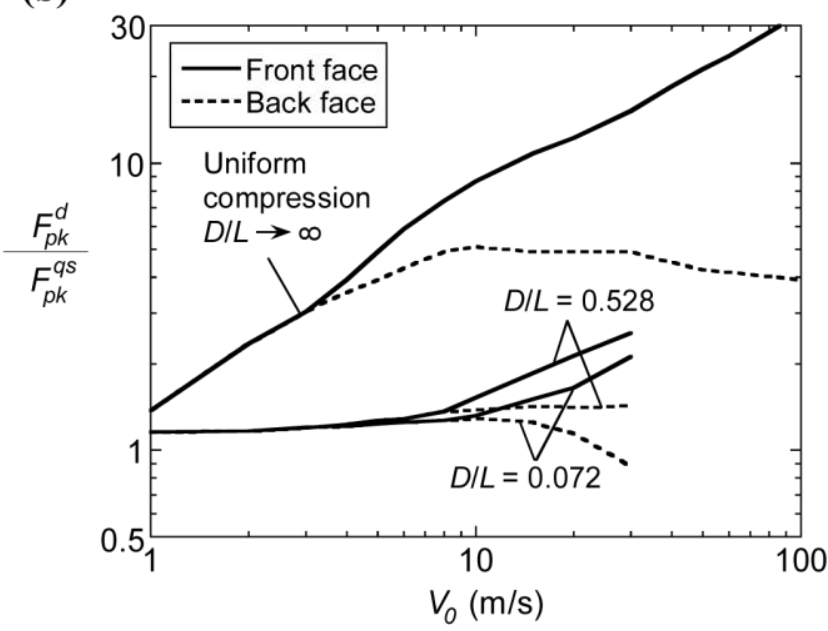

(d)

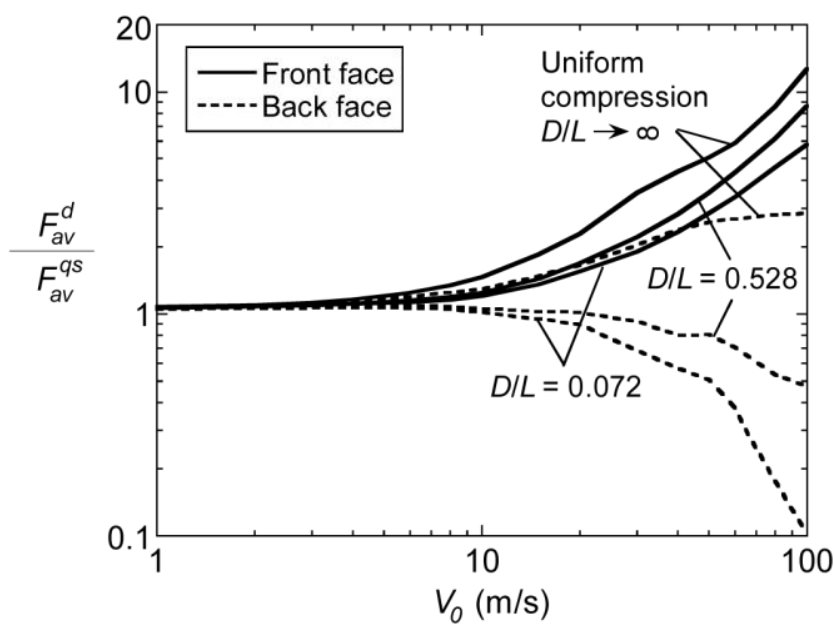

Fig. 9. Influence of the normalised diameter $D / L$ of the circular punch on the normalised initial peak load for (a) the corrugated core and (b) the Y-frame core. Likewise, the influence of $D / L$ on the normalised average load up to $\delta / c=0.2$ is shown for (c) the corrugated core and (d) the Y-frame core. 
(a)

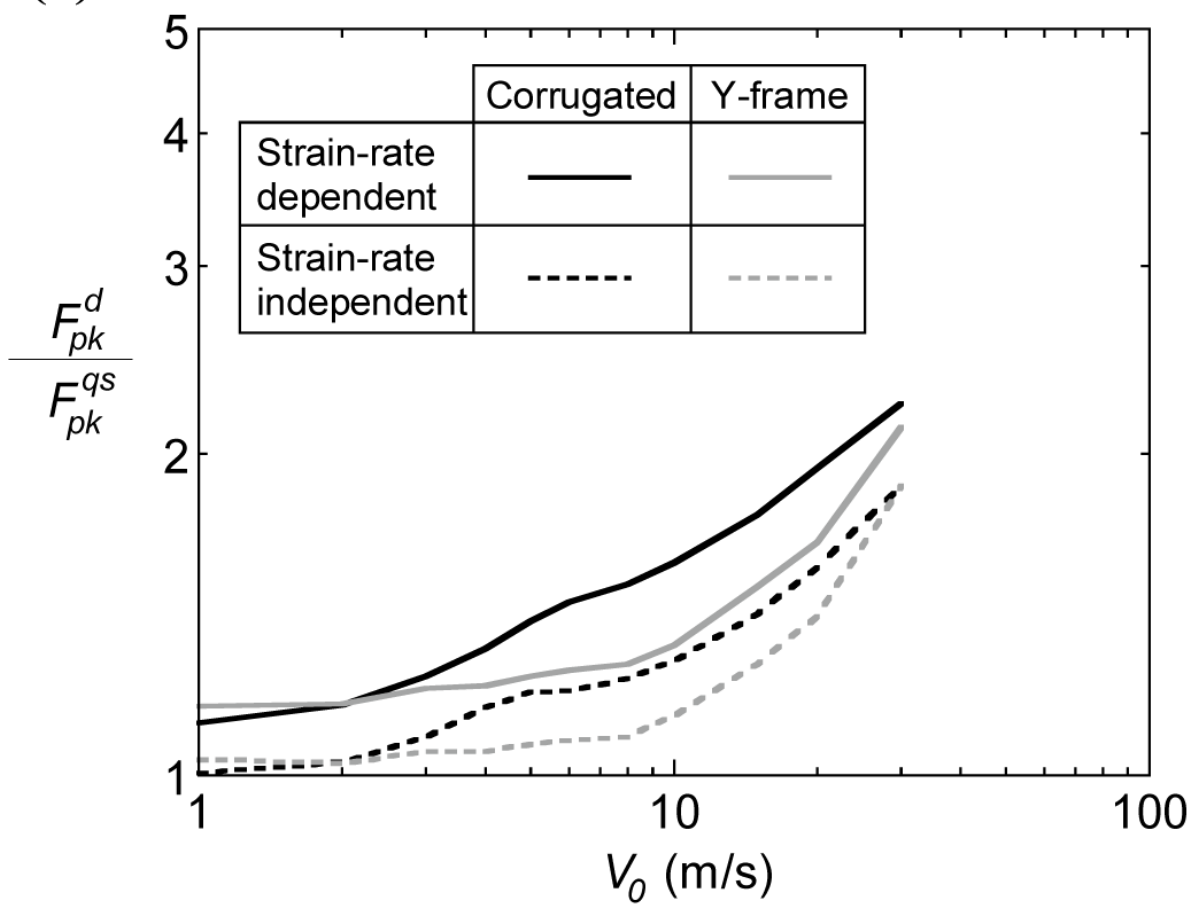

(b)

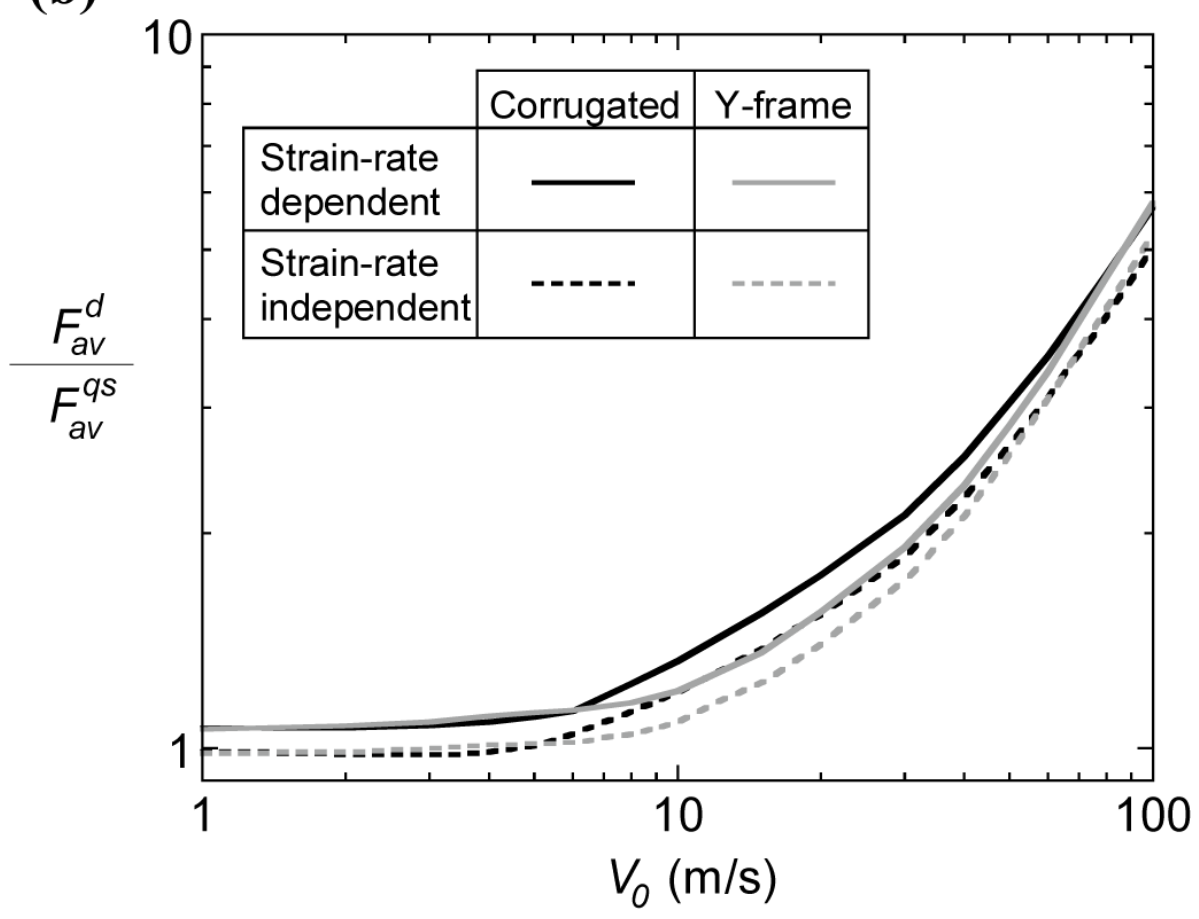

Fig. 10. Influence of material strain-rate sensitivity on (a) the normalised initial peak load and (b) the normalised average load up to $\delta / c=0.2$. Results are shown for sandwich panels with a corrugated core or a Y-frame core indented by a circular punch of normalised diameter $D / L=0.072$, and only the force applied on the front face is shown. 


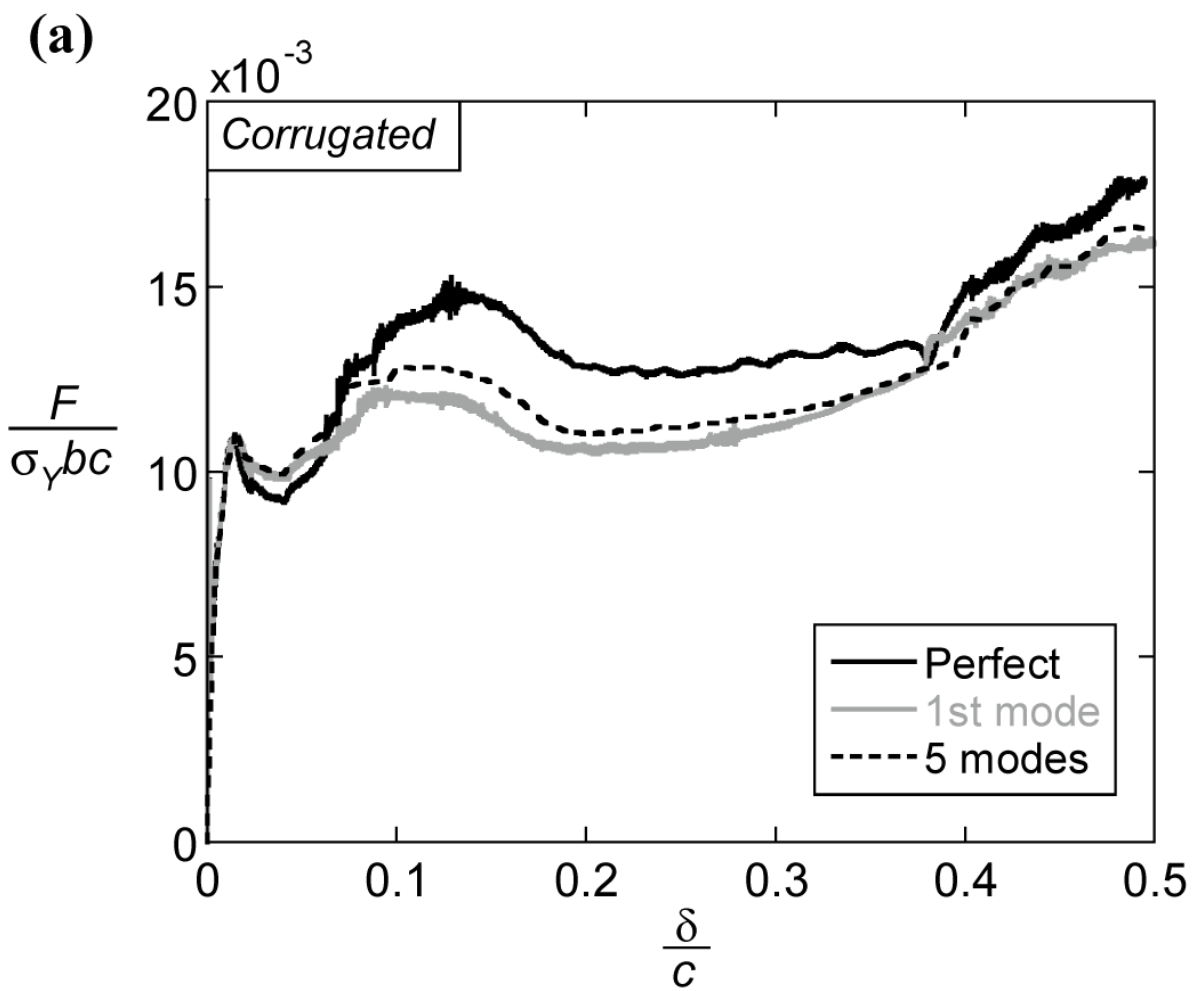

(b)

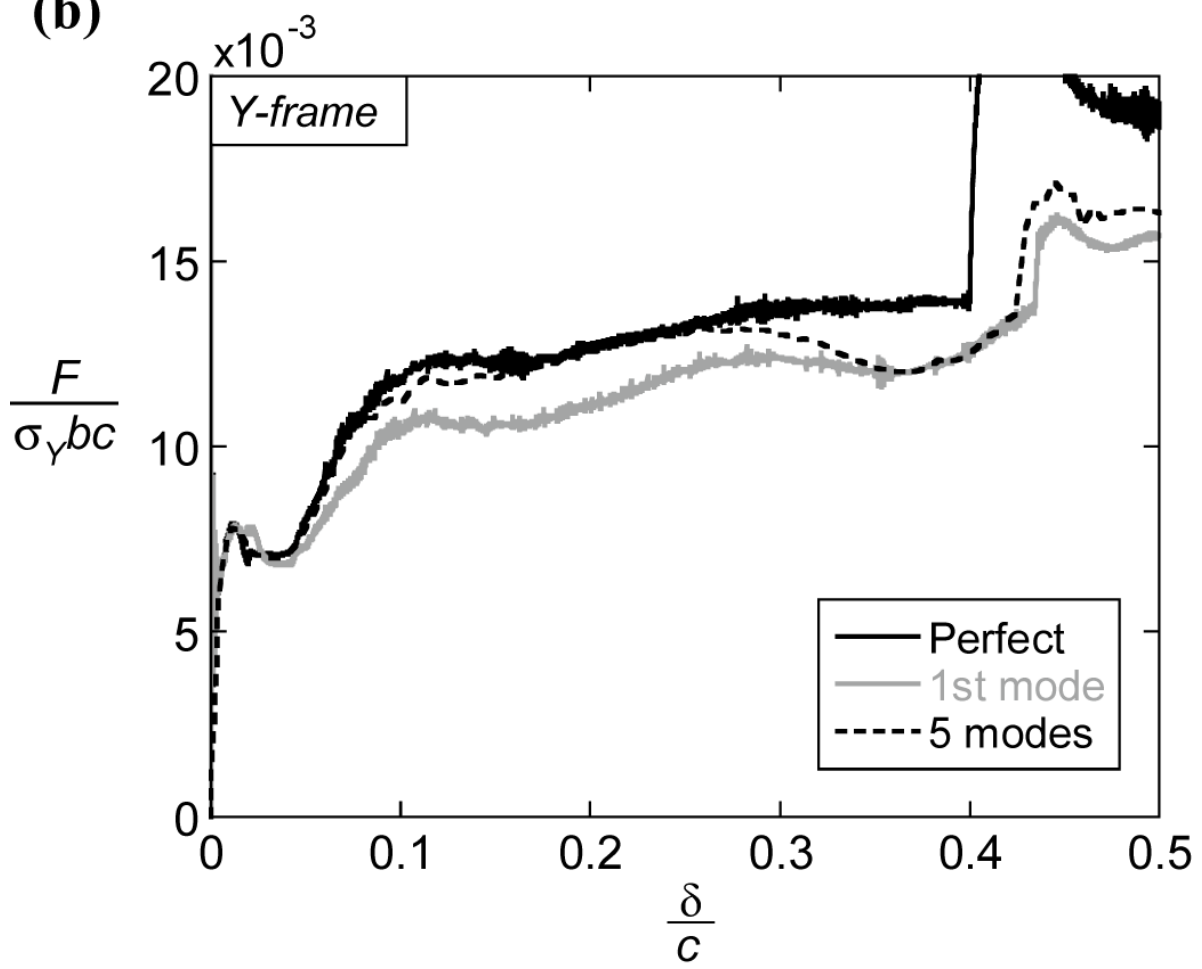

Fig. A.1. Influence of imperfection shape upon the response of sandwich panels indented by a circular punch of normalised diameter $D / L=0.072$ at $V_{0}=10 \mathrm{~m} / \mathrm{s}$. In all cases, the imperfection amplitude is $\zeta=t=6 \mathrm{~mm}$. The force on the front face is shown for (a) corrugated core and (b) Yframe core. 


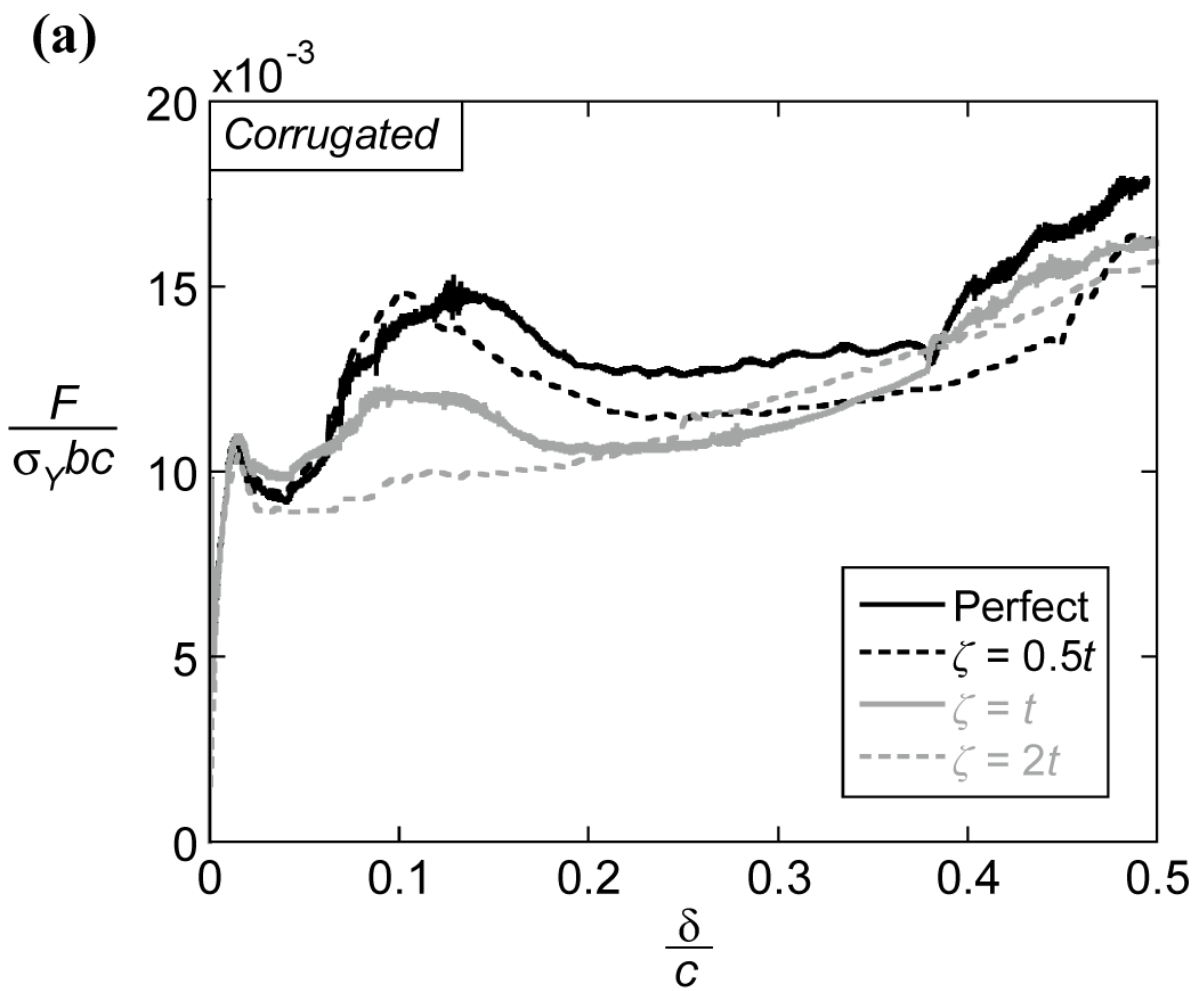

(b)

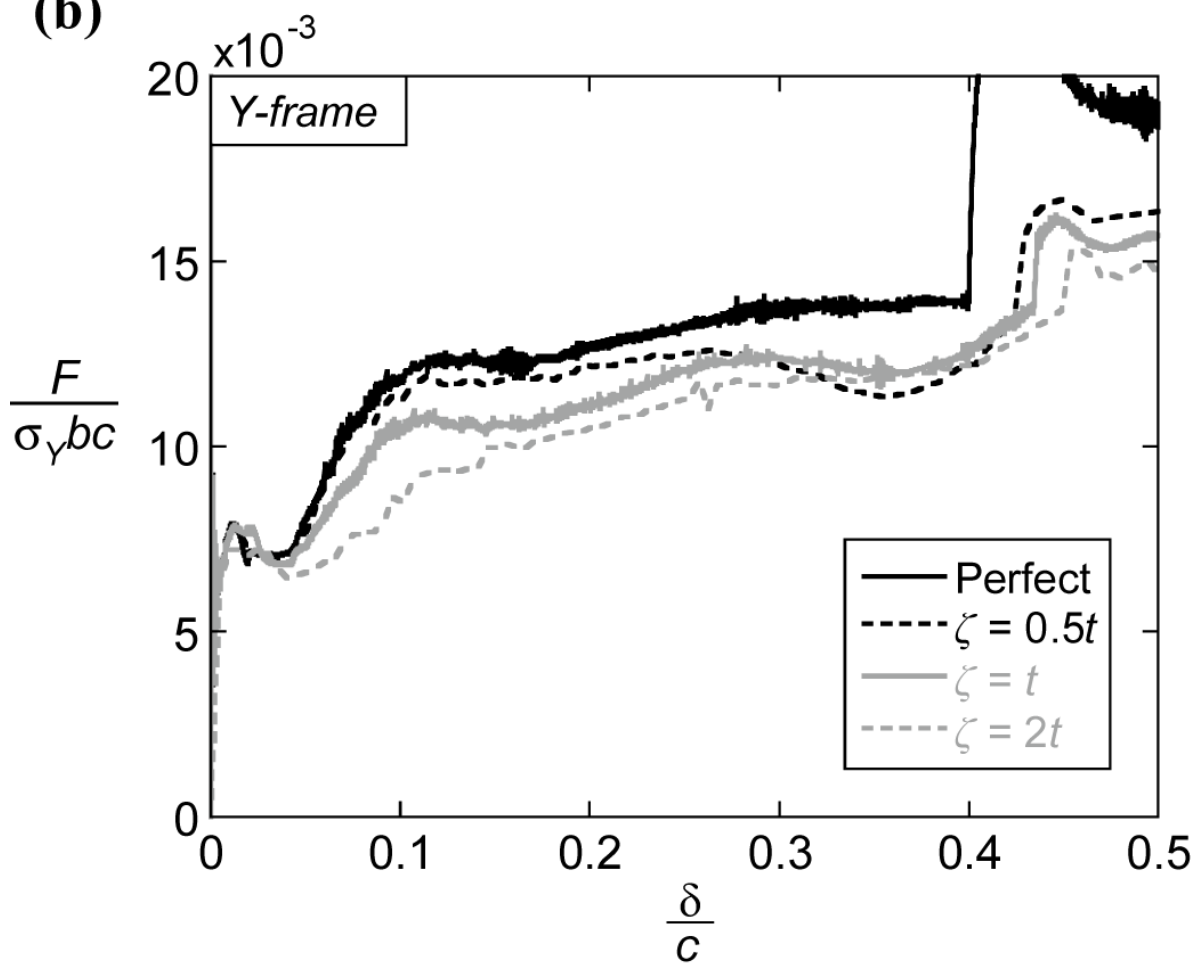

Fig. A.2. Influence of imperfection amplitude upon the response of sandwich panels indented by a circular punch of normalised diameter $D / L=0.072$ at $V_{0}=10 \mathrm{~m} / \mathrm{s}$. In all cases, the imperfection shape is in the form of the first buckling mode. The force on the front face is shown for (a) corrugated core and (b) Y-frame core. 


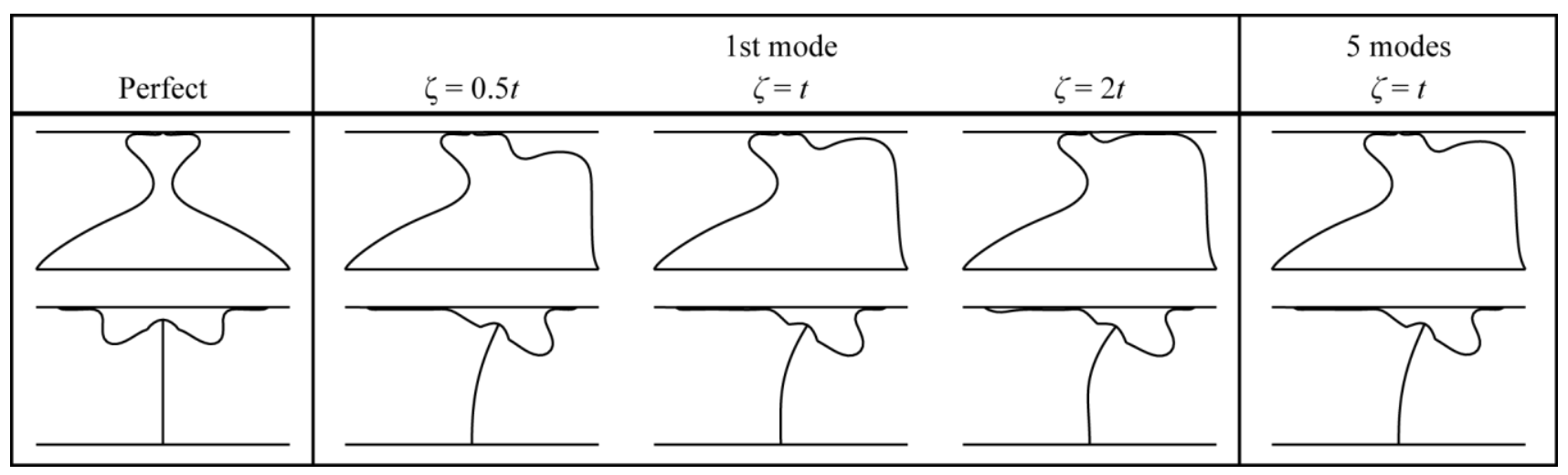

Table A.1. Influence of a geometric imperfection upon the deformed geometry of sandwich panels indented by a circular punch of normalised diameter $D / L=0.072$ at $V_{0}=10 \mathrm{~m} / \mathrm{s}$. The images show the cross-section of the panel underneath the punch. Results are given for corrugated and Y-frame cores at $\delta / c=0.35$. 